\title{
DA OCCIDENTE A ORIENTE. ALCUNI CASI DI CIRCOLAZIONE E RICEZIONE DI MODELLI NELL'ARCHITETTURA E NELLA SCULTURA DELL'ALBANIA FRA XII E XIV SECOLO."
}

\section{GIANVITO CAMPOBASSO}

UDC: $72.033 .4(496.5) " 11 / 13 "$

Review 730.033.4(496.5)"11/13"

Manuscript received: 02. 03. 2016.

Revised manuscript accepted: 21. 04. 2016.

DOI: 10.1484/J.HAM.5.111331
G. Campobasso

Université de Fribourg / Universität Freiburg Site Miséricorde, bureau 2022 Av. de l'Europe, 20 $\mathrm{CH}-1700$ Fribourg, Switzerland gianvito.campobasso@unifr.ch

This article aims to define some dynamics about culturallartistic links in the Southern Adriatic Sea, focusing on the Albanian territories in the Late Middle Ages. In this framework, not well known case studies are presented as emblematic of the circulation of ideas and models, hypothesizing the original background of workshops and commissioners where possible, to better understand some transfers. Sporadic and fragmentary evidences or ruins, in the best cases highly stratified, testify how much those territories where included in a network of relations with the Balkan coast as well with the oversea. Those settlements were scattered along the main routes, mostly defined by rivers dotted by harbors, at the very beginning of transbalkan axes, privileged places for cultural and economical encounters, into the cosmopolite and bi-confessional Albanian society.

Keywords: Late Middle Ages Albania, Benedictines, Apulia, cultural transfers.

Nell'ambito dei più recenti studi e nel contemporaneo dibattito sull'arte balcanica e le sue radici, è molto marginale l'interesse per l'Albania medievale. Piuttosto vivo invece per altri periodi storici (età greca, romana, tardo-antica o ottomana), che hanno prodotto significativi contributi per la conoscenza delle passate società mediterranee su quel territorio. Studiosi rinomati, università e istituzioni straniere, ne hanno inserito i casi di studio nel dibattito internazionale, ricucendo le distanze con l'accademia albanese ${ }^{1}$.

Sul fronte del medioevo, come detto, tale vivacità è di molto ridotta, spesso relegata alle sole manifestazioni della cultura bizantina. Un discorso a parte merita il valido lavoro della scuola locale, il quale però dovrebbe essere meglio inserito in una logica comparativa, non solo delle manifestazioni artistiche, ma anche della critica.
Eppure dal secolo scorso si assiste allo sviluppo degli studi sulla regione storica della Dalmatia, in un'ottica globale ed interdisciplinare, purtroppo dimenticando che quella regione incluse negli ultimi secoli del medioevo anche l'attuale Albania settentrionale, le cui vicende e manifestazioni artistiche andrebbero meglio contestualizzate nell'ambito dei Balcani cattolici e dei rapporti adriatici e ultradriatici. Quando si parla di arte romanica e gotica, più ci si spinge a sud di Cattaro, tanto meno sono note le manifestazioni artistiche del secondo medioevo sulla fascia costiera montenegrina ed albanese, particolarmente fra Scutari e Durazzo dove i fiumi Drin e Mati segnarono il confine fra Dalmatia e Arbanon'. Quest'ultima regione poi, incuneata sul confine fra il litorale dalmatico e cattolico, la composita realtà dei Balcani greco-ortodossi (Epiro, Macedonia, Serbia), divenne

\footnotetext{
* Questo lavoro affonda le radici in una ricerca cominciata in seno al dottorato in Storia dell'arte comparata, civiltà e culture dei paesi mediterranei (coordinatore prof.ssa M.S. Calò Mariani), con la tesi Sulle relazioni artistiche fra le due sponde adriatiche nel medioevo: Albania e Puglia (tutor prof.ssa A. Pepe), discussa presso l'Università degli Studi di Bari "Aldo Moro" nel 2011. Attualmente prosegue nell'ambito di un progetto di ricerca finanziato dal Fondo Nazionale Svizzero presso l'Università di Friburgo, Von Venedig zum Heiligen Land. Ausstattung und Wahrnehmung von Pilgerorten an der Mittelmeerküste (1300-1550) (SNF-Projekt 2014-2017), diretto dal prof. Michele Bacci. Questo progetto si propone di esplorare i santuari costieri e le città portuali nell'ambito dei peregrinagia maritima, cercando di restituire il tessuto delle devozioni per mare seguite dai pellegrini sulle rotte per la Terrasanta. Una "topografia sacra" delle coste del Mediterraneo orientale che diventa anche strumento per facilitare la comprensione dei transfer artistici, culturali e concettuali che agli occhi dei viaggiatori, durante il tardo medioevo, dovevano essere per lo più comprensibili e risvegliare loro una vasta gamma di emozioni.

${ }^{1}$ Qualche eccezione è riscontrabile da qualche anno a questa parte, per lo più dovute a campagne archeologiche relative all'alto medioevo o circoscritte a pochi monumenti bizantini. Si veda a mo' di esempio l'ultimo ricco congresso tenutosi gli scorsi 20-23 maggio 2015 presso il Museo Nazionale di Tirana L'Illyrie Méridionale et l'Épire dans l'Antiquité - VIe Colloque International che con il sostegno di importanti istituzioni culturali francesi e locali ha abbracciato un periodo che va dalla Preistoria fino a lambire il Medioevo. L'attività pluriennale di scavo e le relative pubblicazioni di Pascale Chevalier dell'Università di Clermont-Ferrand riguardanti l'insediamento di Byllis e l'Albania paleocristiana; oppure la redazione di una carta archeologica della costa e dei fondali d'Albania, obiettivo del progetto Liburna della missione archeologica italiana dell'Università di Foggia, diretta dal prof. Giuliano Volpe. Da alcuni anni è attiva una campagna di scavo guidata dall'École francaise de Rome sui siti di Komani e Lezha, con risultati che abbracciano i secoli centrali del medioevo. Così come l'attività del compianto prof. Gianclaudio Macchiarella e del Centro Interdisciplinare di Studi Balcanici e Internazionali dell'Università Ca' Foscari di Venezia, rivolta ai problemi della conservazione del patrimonio bizantino, post-bizantino e d'età ottomana.

${ }^{2}$ L'Arbanon era l'entroterra montuoso dell'Albania centrosettentrionale, storicamente abitato dalle popolazioni autoctone. Dal IX secolo era parte del Tema di Durazzo. Nel XIII secolo si estendeva grossomodo fra il fiume Drin a nord e la catena dei monti Akrocerauni a sud presso Valona. K., FRASHËRI, Les territoires albanais dans le haut moyen age, in Studia Albanica, 2,1982, pp. 93-107. A. DUCELLIER, L'Arbanon et les Albanais au XIe siècle, in ID., L'Albanie

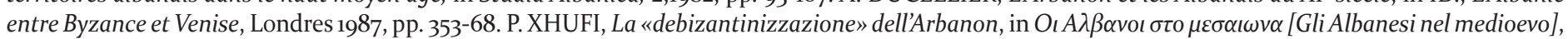

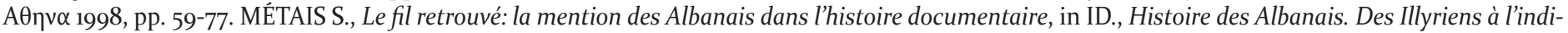
pendance du Kosovo, Villeneuve-d'Ascq 2006, pp. 184-187.
} 


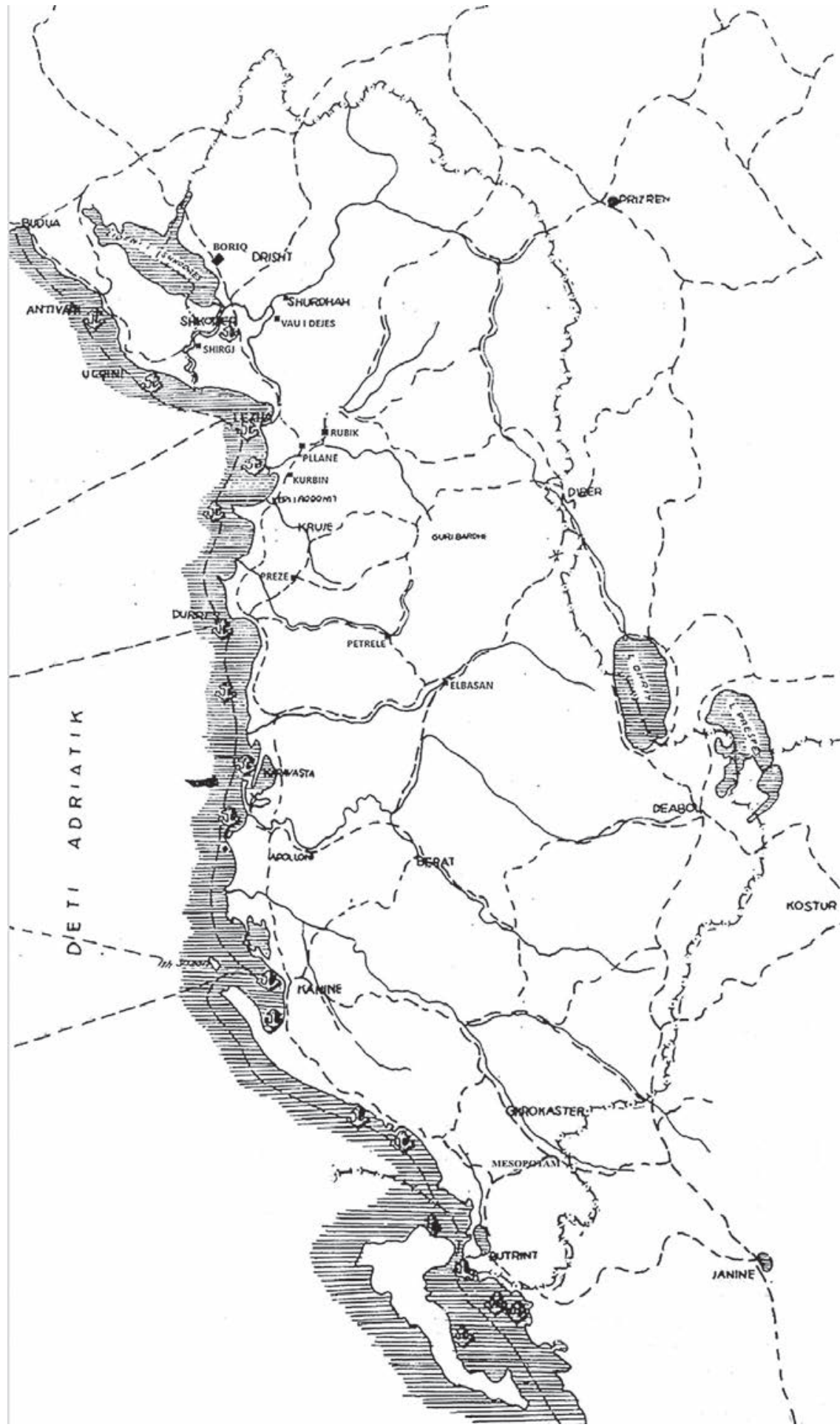

Fig. 1. Albania, i porti e la viabilità medievale.

una sorta di area cuscinetto, biconfessionale, aperta a più orientamenti culturali. In quei secoli il cattolicesimo cercava di farsi strada, approfittando anche del recedere di Bisanzio, della feudalizzazione della società introdotta dal susseguirsi di dominatori occidentali e la gravitazione sul sistema dei commerci adriatici fra Ragusa, Venezia e l'opposta sponda italiana. Ciò facilitò fra la Dalmatia albanese e l'Arbanon la penetrazione di modelli dell'arte occidentale che permisero a quelle società di esprimersi spesso seguendo le vicende artistico-culturali dell'Adriatico latino e cattolico; altre volte mettendo in atto quel chiaro sincretismo, tipicamente balcanico, di un'arte di frontiera che costruiva un proprio lessico selezionando da una o dall'altra tradizione culturale, a seconda della convenienza e dei messaggi che si voleva lanciare, oggi non più facilmente decriptabili. Questo articolo, costituisce un primo e ancora parziale giro d'orizzonti nel contesto albanese, nel tentativo di ricucire quelle realtà artistiche con panorami più noti di entrambe le coste adriatiche. Si concentra principalmente nel mettere in risalto la circolazione di modelli relativi alle formule architettoniche e alla scultura, mentre la pittura conserva ulteriori e maggiori problematiche che impongono uno studio a parte 3 .

Nelle pagine che seguono, come anticipato, cercherò di puntare l'attenzione su un territorio piuttosto ampio che va dall'estremo lembo meridionale della Dalmatia, oggi incluso nell'Albania, fra il Lago di Scutari ed i fiumi Buna, Drin e Mati, frontiere mobili nel medioevo; fino alla fascia costiera meridionale dell'Epiro albanese, estesa a fronteggiare l'isola di Corfù e lo Stretto di Butrinto, segnando il passaggio dall'Adriatico allo Ionio (fig. 1). L'intento è quello di recuperare, per dirla con il Cordignano, un primo tessuto della "geografia sacra” dell'Albania medievale, comprensivo però anche d'insediamenti dediti al culto greco. Questa geografia, o meglio "topografia sacra”, è a forza di cose parziale a causa della dispersione dei documenti e per la devastazione subita dai contesti cristiani negli ultimi cinque secoli. In questa sede si vuol proporre una prima mappatura di insediamenti religiosi posti sui principali assi di comunicazione, in alcuni casi corrispondenti a corsi d'acqua parzialmente o stagionalmente navigabili, dunque in un sistema fatto anche di scali fluviali. Vi si svilupparono particolari interazioni culturali fra Oriente ed Occidente, riflesso di un carattere o identità in fieri e di una società di confine che, in più momenti storici, come ora se vogliamo, dimostra di subire la forte attrazione dell'Europa occidentale.

(...) L'Albania è tutta seminata di rovine; si potrebbe dire anzi che è tutta una gigantesca collezione di ruderi e di frammenti. Città sepolte sotto le pietre franate del monte vicino o sotto la terra accumulata dalle alluvioni; necropoli avvolte da un nimbo fantastico di leggende, dalle quali di tanto in tanto balena qualche sprazzo inatteso di luce sopra remote antichità; mura ciclopiche, che nè i barbari nè le tempeste hanno potuto del tutto demolire; fianchi di fortezze e archi di ponti che mostrano l'opera di successive culture o civiltà. Codesta serie ininterrotta di avvenimenti tempestosi lasciò senza dubbio successivamente non una ma innumerevoli impronte, più o meno profonde, le

${ }^{3}$ A tale proposito mi sia concesso di rimandare al mio recente lavoro L'Albanie des Anjou. Alcuni aspetti di cultura occidentale nel Levante adriatico fra XIII e XIV secolo, in Iconographica, 14, 2015, pp. 72-99, che offre anche una prima disamina su alcune problematiche della pittura albanese in quei secoli, legate alle ambizioni angioine e della loro feudalità. 
quali sommandosi insieme e confondendosi, plasmarono il complesso carattere albanese, non uniforme ma vario come la schiatta e come il genio della cultura e delle costumanze, a seconda del clima della regione abitata, dei popoli vicini, delle condizioni politiche e religiose (...).

(F. Cordignano, in La Civiltà Cattolica, 1929, II,)

\section{1) PORTI ADRIATICI E SEDI VESCOVILI; LA PENETRAZIONE BENEDETTINA AL CONFINE CON BISANZIO.}

Fra XI e XII secolo, andava rafforzandosi l'influenza dei Normanni negli affari mediterranei e Bisanzio dovette farne i conti, soprattutto nelle sue province occidentali. Con l'ingerenza del Basileus estromessa dall'Italia, a seguito della caduta del Catapanato di Bari nel 1071, si sugellava la completa acquisizione del Mezzogiorno italiano da parte del nordico popolo e l'arretrare della linea di confine all'Adriatico orientale. Fra le sue coste si estendeva il potere politico-commerciale dell'infida Venezia, mentre cresceva l'autonomia dei giovani principati balcanici e la relativa influenza sulle ricche città portuali dalmate, mentre altre, pur formalmente incluse nel Thema di Dalmatia ${ }^{4}$, tentavano di perseguire l'autonomia.

Più a sud, il Thema di Durazzo, istituito nel IX secolo ${ }^{5}$ per fronteggiare il dilagare dei Saraceni in Adriatico, risultò pienamente riconvertito nell'ultimo fronte militare bizantino verso Occidente. L'irresistibile avanzata dei Normanni nel tardo XI secolo, sempre in cerca di nuovi feudi ed inclini alla fascinazione dell'Oriente, esperito in Sicilia e in tutto il sud dell'Italia, portò questi ad interessarsi di alcune isole e città di Dalmatia, ma particolarmente ad invadere i territori lungo la Via Egnazia poco prima della Crociata, la quale poi offrì un pretesto per allargare le operazioni dall'oltreadriatico a Gerusalemme ed Antiochia ${ }^{6}$. La spinta normanna riprese con re Guglielmo II che nel 1185 conquistò un'ampia fascia terriera da Durazzo a Salonicco tanto che ancora l'imperatore Enrico VI se ne proclamava sovrano ${ }^{7}$.

Dal punto di vista religioso, in quei due secoli, una riorganizzazione delle sedi vescovili della Dalmatia, coordinata dalla Curia Romana, andò in parallelo a tali eventi e all'es- pansionismo del principato cattolico di Dioclea ai danni del Thema di Durazzo. L'azione congiunta di questi fattori erose potere e territori all'Impero Bizantino ed al controllo del patriarcato greco di Durazzo, specie dove prosperavano comunità di rito e lingua latine, aprendo nuovi spazi e vie commerciali sfruttate anche dai monaci. Nel 1022 papa Benedetto VIII dichiarava Antibari e Dulcigno sotto l'autorità dell'arcivescovo di Ragusa, liberata dalla suffraganeità verso Spalato. Nel corso del secolo, anche per il consolidamento politico del principato serbo di Dioclea, emerse sempre più l'importanza della diocesi di Antivari-Dioclea che estese la sua giurisdizione sulle sedi vescovili della costa dalmata meridionale e intorno al Lago di Scutari, una volta parte del Thema di Durazzo e suffraganee di quella metropolia. Ciò fu possibile anche per l'annessione a quel principato proprio di Scutari e dei territori lungo il Drin ${ }^{8}$.

Le comunità e le aristocrazie cattoliche nel nord dell'Albania, appoggiarono la gemmazione di nuove diocesi ed edifici di culto, ancora fino a tutto il XIV secolo; parallelamente si accrebbe l'espansione degli Ordini Monastici alla ricerca di luoghi adatti alla vita contemplativa, fertili campagne e feudi per la loro economia9 . Risalendo antichi itinerari utilizzati dalle legioni romane per conquistare i Balcani, i Benedettini penetrarono dalla costa verso l'interno montuoso del paese, fondando insediamenti ben aldilà del confine segnato dall'ingerenza delle diocesi cattoliche di Dioclea.

Dalle comunità latine del litorale, dai nuovi vescovati fra il Lago di Scutari ed il corso del Drin (l'antico itinerario romano Lissus-Naissus ${ }^{10}$ ), o dai monasteri, promanava la cultura romana, estendendosi verso l'Arbanon. Una nuova stagione di contatti a triplo filo, politici, religiosi e commerciali si andava ridefinendo, tanto con l'Italia ma anche con le città dalmate, scavalcando i confini ormai labili fra Bisanzio e l'Occidente.

Nella regione d'Arbanon, nucleo storico dell'Albania e parte del Thema di Durazzo poi Provintia Dyrrachii et Arbani, rimasta più a margine delle invasioni slave anche per l'inaccessibilità dei luoghi, apostasie e conversioni sono documentate solo dal XII secolo, ma potrebbe trattarsi di un fenomeno ben più antico. È noto il caso di alcuni componen-

${ }^{4}$ Il Thema di Dalmatia, come quello di Dyrracchion risale al IX secolo. J. FERLUGA, L'amministrazione bizantina in Dalmazia, Venezia 1978. P. STEPHENSON, Byzanntium's balkan frontier. A Political Study of the Northern Balkans, 900-1204, Cambridge 2000.

5 J. FERLUGA, Sur la date de la création du thème de Dyrrachium, Actes du XII e congrès international d'etudes byzantines, Ochride 10-16 septembre 1961, Beograd 1964, II, pp. 82-92. A. DUCELLIER, La façade maritime de l'Albanie Aux Moyen Âge. Durazzo et Valona du XI' au XVe siècle, Thessalonique 1981, pp. 92-93. ${ }^{6}$ Cfr. F. NEVEUX, L'espansione in Europa; V. VON FALKENHAUSEN, I Rapporti con Bisanzio, entrambi in M. D'ONOFRIO (dir.), I Normanni popolo d'Europa MXXX-MCC, Venezia 1994, pp. 98-105; 350-355. G. GALASSO, La politica estera del Regno di Sicilia dai Normanni a Federico II, in ID., Medioevo euro-mediterraneo e Mezzogiorno d'Italia da Giustiniano a Federico II, Roma-Bari 2009, pp. 344-391. R. RUSSO, Boemondo d'Altavilla un pugliese alla prima crociata, Barletta 2009, pp. 51-61, 253-260.

${ }^{7}$ L'imperatore Enrico VI sposò Costanza, ultima discendente della stirpe sovrana degli Altavilla. D. ABULAFIA, Federico II. Un imperatore medievale, Torino 1990, p. 66. F. NEVEUX F., op. cit. (n. 6). P. XHUFI, L'aggancio ad est: Manfredi Hohenstaufen in Albania, in L. BALLETTO (dir.), Oriente ed Occidente tra Medioevo ed Età moderna. Studi in onore di Geo Pistarino, Genova 1997, pp. 1233- 1256.

${ }^{8}$ G. FEDALTO, La situazione canonico-giurisdizionale di Dalmazia ed Albania medievali nei rapporti con Roma e Costantinopoli, in Rivista storica del Mezzogiorno, 1976-77, pp. 85-105. A. DUCELLIER, op. cit. (n. 5), pp. XII, 1o. P. STEPHENSON, op. cit. (n. 4), p. 7o. Sullo sviluppo delle corti in area dalmata e la riforma della chiesa di Dalmatia mediata anche dall'Ordine Benedettino cfr. S. GIOANNI, Les cours croates et la réforme de l'église dalmate (IX ${ }^{e}-X I{ }^{e}$ siècle) structures, hommes et doctrines, in Le corti nell'alto medioevo, Settimane di Studio della Fondazione Centro Italiano di Studi sull'Alto Medioevo, Spoleto, 24-29 aprile 2014, 62, Spoleto 2015, pp. 319-352.

${ }_{9}$ Queste diocesi latine consolidatesi a partire dall'XI secolo, oltre il confine nord dell'Arbanon: Antibari, Dulcigno, Scutari, Drivasto, Sarda, Dania costituivano quello chiamato da Xhufi il "triangolo cattolico albanese". P. XHUFI, Krishtërimi roman në Shqipëri, shek. VI-XVI, in Krishtërimi ndër Shqiptarë, Simpozium Ndërkombëtar, Tiranë, 16-19 Nëntor 1999, Shkodër 2000, pp. 89-99.

${ }^{10}$ Univa le attuali città di Lezha in Albania e Nish in Serbia. H. STUART JONES, The historical interpretation of the reliefs of the Trajans Colum, in Papers of the British School at Rome, 5, 1910, pp. 433-459. L., PËRZITHA Kështjella të periudhës antike të vonë përgjatë rrugës Lissus-Naissus (riass. Late antiquity castles along the Lissus-Naissus road), in Monumentet, 1992-1999, pp. 85-112. F. VANNI, Le vie terrestri dei Balcani. Alcuni indizi di continuità nel tempo, in De Strata Francigena. Studi e ricerche sulle vie di pellegrinaggio del Medioevo. Annuario del Centro Studi Romei, 14/1, 2006. pp. 17- 25. 
ti della famiglia Skura, aristocratici che passarono al culto romano nel corso di quel secolo" ${ }^{11}$, potenti patrocinatori di un sacello a carattere funerario: la chiesa di S. Maria di Brar, nell'attuale toponomastica, o Berrari dai documenti ${ }^{12}$, celata fra le montagne che cingono la Piana di Tirana. Le relazioni e le ricognizioni compiute dall'Instituti i Monumenteve të Kulturës di Tirana confermano lo stato di completa distruzione dell'edificio collassato su se stesso, e la dispersione dei materiali di crollo ${ }^{13}$. Solo alcune creste murarie con illeggibili lacerti pittorici sembrerebbero restituire un'apparente planimetria a camera dell'ambiente. Fortunatamente, alcuni frammenti dell'arredo scultoreo sono conservati presso il Museo Nazionale di Tirana, fra questi spicca il fronte di un sarcofago decorato a bassorilievo da croci latine. Ai bordi, due iscrizioni epigrafiche pro remedio animae in greco e in latino, identiche nei contenuti, riecheggiano una vicenda umana svoltasi sul crinale fra due culture ricordando Michele Skura, il quale ascese all'alta carica bizantina di sebasto, con la sua famiglia. Il testo latino dice così:

Or(e) sua et cum fili(i)s suis memento d(omi)ne famulo tuo Michael Sevasto Sguru cum ux(ore).

Al 1166 risale la prima menzione documentaria di un monastero benedettino in Arbanon, Sancti Salvatoris Arbanensis, che registra anche un episcopis Lazaro Arbanen$\operatorname{sis}^{14}$. Un atto di papa Alessandro III, redatto il 3 gennaio 1168 , segnala una comunità cattolica a Durazzo con tanto di abate: abbatibus et ceteris latinis tam clericis quam laicis apud Durachium commorantibus ${ }^{15}$ e Ducellier ricorda che almeno da quel secolo abbiamo notizie di amalfitani e veneziani dimoranti in quella città ${ }^{16}$.

I Benedettini nel corso del XII e XIII secolo risultano quindi essere già diffusi sui principali assi: quello costiero, ricco e cosmopolita perché incluso negli scambi adriatici, ma anche lungo itinerari interni rivolti ai commerci e alle comunicazioni transbalcaniche.

Seguendo un diverticulum meridionale dell'Itinerarium Lissus-Naissus, principalmente segnato dal corso del fiume
Mati e dal suo affluente Fan, la Regola penetrò fino all'attuale Mirdita, cuore selvaggio e montagnoso dell'Arbanon (S. Nicola in Mati, S. Salvatore di Rubik e S. Alessandro in Monte di Orosh, sono solo alcuni nomi di abbazie, ma molte altre ne restano che si fatica a localizzare). Trattasi di insediamenti da contestualizzare nel generale impulso che l'Ordine ebbe in tutta Europa fra XI e XIII secolo, strumento di ingerenza e riforma della Curia Papale sulla costa balcanica, da cui dipese il nuovo assetto e la moltiplicazione delle sedi vescovili. Fenomeni che andavano in parallelo al reciproco appoggio fra Roma e le aristocrazie locali ${ }^{17}$.

Le diocesi sorte nella Dioclea albanese si inquadrano in un periodo di espansione che l'Ordine ebbe lungo l'intera costa dalmata, con le prime fondazioni nate almeno dal IX -X secolo ${ }^{18}$ come filiazioni di abbazie italiane, non di rado pugliesi, e con il supporto dell'aristocrazia locale in concerto con le alte gerarchie dell'Ordine e con Roma. Nel secolo successivo le principali città costiere di Dalmatia potevano già annoverare monasteri sia maschili che femminili eretti per impulso di Montecassino o di altri monasteri benedettini del sud Italia' ${ }^{19}$. È il caso dal 968 di San Crisogono di Zara, cassinese; mentre l'abazia di S. Maria di Tremiti possedeva un'omonima dipendenza sull'isola di Lacroma di fronte a Ragusa, da cui un'altra dipendenza venne fondata sull'isola di Biševo. A Ragusa il monastero di S. Maria de Rabiata venne affidato ai Cassinesi e dovette assurgere a particolare importanza tanto da essere riportato nella porta bronzea del 1071 della basilica di Montecassino. Ai Monaci Pulsanesi fu concessa l'intera isola di Meleda, di fronte Ragusa, dove sorse una nota abbazia ${ }^{20}$. Taluni di questi monasteri si affermarono come scriptoria da cui uscirono, fra XI e XIII secolo, codici miniati di alto pregio, scritti in una beneventana mediata da modelli pugliesi ${ }^{21}$, sottolineando, una volta di più, una direttrice culturale rivolta al Mezzogiorno italiano che metteva in primo piano la costa della Puglia. A fine XIII secolo l'intervento angioino oltreadriatico fu facilitato anche dall'attività diplomatica dei religiosi con un ruolo preponderante dei Benedettini, i quali mediarono con i

\footnotetext{
"P. XHUFI, op. cit. (n. 9).
}

${ }^{12}$ Da una relazione del 1640, stesa dell'arcivescovo di Croja, fra' Marco Scura (alb. Skura) e probabile discendente del sebasto Michele, si apprende che l'edificio era già in forte stato di degrado: “[...] S. Maria sopra la terra di Berrari anticamente chiesa famosissima di miracoli, e spasso dell'Arciuescouo di Durazzo, quasi distrutta i suoi sudditi tutti Turchi rinegati [...]”. F. CORDIGNANO, Geografia ecclesiastica dell'Albania, dagli ultimi decenni del secolo XVI alla metà del secolo XVII, in Orientalia Christiana, 99, 1934, p. 254.

${ }^{13}$ Mbi shpalljen Monument Kulture i Kategorisë së I (parë) të rrënojave të "Kishës së Shën Mërisë" në fshatin Brar, Tiranë, dhë përcaktimin e zonës mbrojtëse të saj, Tiranë 2008, prot. 1009 (Relazione sullo stato di conservazione della chiesa di S. Maria di Brar nel distretto di Tirana, aggiornata al 2008, protocollo $\mathrm{N}^{\circ} 1009$ dell'archivio I.M.K.). Dalla relazione si apprende come l'edificio sia stato scoperto nel 1982 dagli archeologi Aleksandër Meksi e Damian Komata. ${ }^{14}$ D. FARLATI, Ecclesia Ragusina cum suffraganeis, et Ecclesia Rhiziniensis et Catharensis, in Illyricum Sacrum, tomo 6º Venezia 1800 , p. 433. L. THALLOCZY - C. JIREČEK - M. ŠUFFLAY, Acta et diplomata res Albaniae mediae aetatis illustrantia (d'ora innanzi Acta Albaniae), Vienna 1913, vol. 1, doc. 93.

${ }^{15}$ Acta Albaniae, vol. 1, doc. 98.

${ }^{16}$ A. DUCELLIER, op. cit. (n. 5), pp. 64-75; M. GAGLIONE, Amalfi e Napoli tra alto medioevo ed età angioina, in B. FIGLIUOLO - P. F. SIMBULA (dir.), Interscambi socio-culturali ed economici fra le città marinare d'Italia e d'Occidente, Atti del Convegno Internazionale di Studi in memoria di Ezio Falcone (Amalfi, 14-16 maggio 2011), Amalfi 2014, pp. 33-69. Recentemente M. GAGLIONE, Gli amalfitani a Durazzo, relazione alla Giornata di Studi: Amalfi trecentesca nello spazio mediterraneo, Amalfi, Biblioteca Comunale, 21 novembre 2014.

${ }^{17} \mathrm{~J}$. M. MARTIN, Recherches sur les relations politiques entre l'Italie méridionale et les Balkans pendant le Haut Moyen-Age (Ve-XIIe siècles), in I rapporti politici e diplomatici, atti del Congresso di Ancona - Jesi - Fabriano - Senigallia - S. Marino (28 febbraio - 4 marzo 1987), Roma 1988, pp. 49-70. S. GIOANNI, op. cit. (n. 8)

${ }^{18}$ I. OSTOJIĆ, Relations entre la Venise médiévale et les monastères Bénédictines en Croatie, in PERTUSI A. (dir.), Venezia e il Levante fino al secolo XV, Firenze 1973, vol. II, pp. 583-598. P. STEPHENSON, , op. cit. (n. 4), p. 29.

19 Ibidem. Per Stephenson la più intensa espansione benedettina comincia dal tardo XI secolo, quando sono documentati più di quaranta monasteri nell'area della Dalmatia, con la possibilità che i più antichi di essi possano datare alla prima metà del IX secolo.

${ }^{20}$ P. F. PALUMBO, Le relazioni religiose e chiesastico-giurisdizionali nella storia delle due sponde, in Rivista storica del Mezzogiorno, 11-12, 1976-77, pp. 1-16. V. FORETIĆ, L'Ordine Benedettino quale tramite nei rapporti tra le due Sponde con particolare riguardo al territorio di Ragusa nel medio evo, in Le relazioni religiose e chiesastico-giurisdizionali, Congressi sulle relazioni tra le due Sponde adriatiche, 1, Roma 1979, pp. 130-144.

${ }^{21}$ E. ELBA, Miniatura in Dalmazia. I codici in beneventana (XI-XIII secolo), Bari 2011. 
governi cittadini e con l'aristocrazia locale ${ }^{22}$. Tale dinamica rispecchiava il particolare impegno che il clero, soprattutto regolare, stava profondendo su tutto il territorio italiano e nelle città della sfera d'influenza angioina; in Albania questo contribuì a stringere ancor più i legami col Mezzogiorno italiano ${ }^{23}$.

Lacunosa e complicata è invece la precisa ricostruzione della rete di relazioni e dipendenze degli insediamenti benedettini nel nord dell'Albania, siano esse rivolte alla $\mathrm{Dal}$ matia o direttamente alla penisola italiana. È indubbio che il fenomeno va contestualizzato principalmente nel corso di quei secoli, pendant meridionale della vivace stagione dalmata, anche perchè corrispondente al massimo apogeo dell'Ordine in tutta l'Europa cattolica ${ }^{24}$.

Il documento del 1166, cronaca della consacrazione degli altari della nuova cattedrale di Cattaro, oltre che riportare la notizia dell'esistenza di un'abbazia in Arbanon con un abate inserito in una rete di relazioni con quella città e quella costa, ricorda anche un Petro abbate (Archimandrita) Sanctorum Sergii et Bachii, ovvero un'abbazia dedicata ai martiri siriani sita sul fiume Buna, presso Scutari, oggi confine fra Albania e Montenegro ${ }^{25}$. Mentre nel 1402 scopriamo che l'abbazia di S. Sophia de Genta, riconosciuta dal Cordignano nelle rovine di un insediamento ai bordi del Drin ${ }^{26}$, elesse a Ragusa il suo abate il quale era già procuratore del monastero pulsanese di S. Maria di Meleda ${ }^{27}$.

Il rapido e florido sviluppo dell'Ordine fu anche il riflesso delle attenzioni e pressioni dell'Occidente sul Mediterraneo bizantino. Queste ebbero un ancor maggior impulso a seguito della Quarta Crociata e della Partitio Romaniae che sancirono la creazione di due imperi latini in Oriente, uno di terra, feudale e "franco"; l'altro marittimo e commerciale, veneziano. Una nuova stagione culturale si aprì nei Balcani con la creazione di feudi latini, ma anche stati bizantini nati dalla disgregazione dell'impero e immersi in un clima filoccidentale con cui necessariamente confrontarsi. È l'istituzionalizzazione delle società miste, il momento in cui le due più importanti matrici culturali della storia mediterranea ed europea convergono e si fondono come mai prima, soprattutto nelle aree di confine. Nei Balcani, l'alacre politica romana ebbe risvolti importanti, ben oltre quelli aspettati dalla Crociata e ben aldilà dei confini dell'Impero latino d'Oriente e dei suoi feudi. Per esempio il re bulgaro e quello serbo della nascente dinastia dei Nemanjić si rivolsero al papa al principio del XIII secolo per veder riconosciuto il loro potere e legittimare la propria autonomia, investiti del titolo regio da un legato papale, si adeguarono ad una consuetudine in uso per i sovrani occidentali. Così facendo permettevano una maggiore ingerenza della chiesa di Roma che però, nel caso dei Bulgari, fu totalmente effimera ${ }^{28}$; mentre in Serbia fu funzionale a consolidare le presenze religiose e le diocesi del litorale ed aprì una stagione di politiche matrimoniali dei Nemanjić anche rivolte all'Occidente ${ }^{29}$, creando le premesse di alcuni fenomeni culturali che ebbero riflessi o coinvolsero l'Albania.

Maggiori risultati si ebbero proprio in Albania quando sull'onda emotiva della caduta di Costantinopoli e con l'inclusione di Durazzo nell'impero navale veneziano, rispettando il trend delle conversioni in quell'area, e del ricorso a Roma delle aristocrazie con velleità sovrane, il principe d'Arbanon Dimitri chiese nel 1208 a papa Innocenzo III di essere accolto nella Chiesa Romana, atto primario per il riconoscimento e la legittimazione di un'entità politica sotto il suo comando ${ }^{30}$.

Con queste premesse e a seguito della naturale posizione geografica che sin dai tempi dei Normanni permetteva di cullare ambizioni sull'Oriente, è evidente come l'Albania diventerà un punto cruciale per le potenze adriatiche e italiane con interessi di vario tipo nel Levante mediterraneo: Venezia ed i sovrani napoletani del tardo medioevo, tra cui Carlo d'Angiò, nelleattese di Roma braccio armato del papato nelle politiche orientali. Questi fattori determinarono un particolare clima fatto di continui contatti e di condizioni adatte alla penetrazione del Cattolicesimo, anche quando sono documentati momenti di frizione.

\section{2) LA CORRENTE SETTENTRIONALE: FRA DALMATIA E ARBANON}

Nel disordine generato dal riassetto delle diocesi della Dalmatia meridionale e nella rivalità che emerse fra Ragusa ed Antivari fra XI e XII secolo, la Chiesa di Cattaro si rivolse oltremare, diventando suffraganea dell'arcivescovato di

\footnotetext{
${ }^{22}$ Sul legame fra gli Angiò e l'Ordine Benedettino con tutte le sue diramazioni: A. DUCELLIER, op. cit. (n. 5), pp. 204-211; 230-319. J. P. BOYER, Prédication et état napolitain dans la première moitié du XIVe siècle, e G. VITOLO, Il monachesimo benedettino nel Mezzogiorno angioino: tra crisi e nuove esperienze religiose, entrambi in L'État Angevin, Pouvoir, culture et société entre XIII e et XIVe siècle. Actes du Colloque International organisé par l'American Academy in Rome, l'École Française de Rome, l'Istituto Storico Italiano per il Medio Evo. l'U.M.R. Telemme et l'Université de Provence, l'Università degli Studi di Napoli "Federico II" (Rome-Naples, 7-11 novembre 1995), Roma 1998, pp. 127-157 e pp. 205-220.

${ }^{23}$ G. CAMPOBASSO, op. cit. (n. 3).

${ }^{24}$ Studi monografici relativi all'introduzione dei Benedettini in Albania sono piuttosto carenti e datati. Quelli del Cordignano, preziosissimi, sono però più che altro una raccolta di documenti e notizie locali mediate dal folklore. F. CORDIGNANO, Antichi monasteri benedettini e loro benemerenze in Albania, e ID. Antichi monasteri benedettini in Albania nella tradizione e nelle leggende popolari, entrambi in La civiltà cattolica, 4, 1929, pp. 227-239 e pp. 504-515. Si veda pure CORDIGNANO F., op. cit. (n. 12). Qualche notizia di notevole interesse anche nello studio storico-archeologico-architettonico di A. MEKSI, Arkitektura e kishave të shqipërisë (Shekujt VII-XV), Tiranë 2004. Mancano lavori specifici sulla dinamica dell'espansione dell'Ordine che ne traccino i legami con la Dalmatia, Montecassino e le varie abbazie nell'Italia meridionale ed ovviamente Roma. Ricerche come quella citata di S. GIOANNI, op. cit. (n. 8), sono essenziali perché definiscono e sintetizzano un panorama generale sulla Dalmatia al quale, per forza di cose e alla luce della ricerca in Albania, si legano anche gli insediamenti nel nord di quel Paese.

${ }^{25}$ D. FARLATI, op. cit. (n. 14). Acta Albaniae, op. cit. (n. 14). I. OSTOJIĆ, Benediktinci u Hrvatskoj i ostalim našim krajevima. Sv. 2: Benediktinci u Dalmaciji, Split - Tkon, Benediktinski Priorat 1968, pp. 522-527.

${ }^{26}$ F. CORDIGNANO, Antichi monasteri benedettini e loro benemerenze... op. cit. (n. 24).

${ }^{27}$ Acta Albaniae, vol. 2, doc. 685 .

${ }^{28}$ M. SPREMIĆ, La Penisola Balcanica tra Oriente e Occidente del secolo XIII, in Medievalia, 1, 1980, pp. 35-48.

${ }^{29}$ S. ĆIRKOVIĆ, I Serbi nel Medioevo, Milano 1992.

${ }^{30}$ P. XHUFI, op. cit. (n. 9).
} 
Bari, “(...) demum seculo duodecimo attributa fuit Metropoli Bariensi (...)" ricorda il Farlati ${ }^{31}$. Ancora oggi questo legame risulta particolarmente sottovalutato dalla storiografia di ambito storico-artistico, certamente a causa della scarsità di documenti circostanziati e delle frammentarie testimonianze materiali. Tale suffraganeità, contrastata ed interferita dalla diocesi di Ragusa ${ }^{32}$, sembra particolarmente stretta e concreta nel secondo XII secolo 33 , quando le due città frontaliere firmarono anche un accordo commerciale "bilaterale" alla fine di quel secolo, ampliando lo spettro dei contatti transandriatici34. Dal 1186 al 1355 Cattaro poi riconobbe la sovranità serba ${ }^{35}$, in concomitanza con i secoli di massimo fulgore di quel regno che si espresse con le manifestazioni artistiche dovute alle committenze della stessa famiglia reale dei Nemanjić, pii frequentatori e offerenti della Basilica barese di S. Nicola, protettore della dinastia ${ }^{36}$. Molteplici e disastrosi terremoti hanno colpito la cattedrale cattarense più volte nei secoli, come altre chiese del litorale, per tale ragione oggi risulta molto alterata dalle sue forme originarie, quando nel 1166 e dopo un ventennio circa di lavori, si procedette alla (ri) consacrazione ${ }^{37}$. La chiesa fu edificata in forme romaniche che guardavano oltreadritico e ai complessi eretti nel meridione normanno, ma non solo ${ }^{38}$. Reminiscenze lombarde e dell'architettura bizantina erano il frutto di un cantiere cosmopolita che rispecchiava una società mista, posta su un'area di confine ed entro traffici commerciali ad ampio raggio. Per tale ragioni la città si espresse con "un'arte di frontiera", trasmettendo alcune novità che dal litorale attecchirono in nuce anche nell'entroterra serbo, con risultati ibridi. Nella Rasha dei Nemanjić le forme architettoniche e le soluzioni strutturali, così come la scultura, erano la conseguenza di maestranze specializzate che provenivano dalle aree costiere e che declinavano il proprio know-how in edifici pensati per il rito ortodosso e decorati da pittori bizantini, questi invece reclutati nei maggiori centri dell'impero.
Il documento relativo alla consacrazione del S. Trifone inoltre, ricorda i prelati del litorale balcanico che accorsero alla celebrazione, (...) cum tribus episcopis, E septem Abbatibus vicinarum circa regionum (...) ${ }^{39}$, fra di essi l'abate del monastero d'Arbanon, Georgio abbate Sancti Salvatoris Arbanensis. Questo ebbe certamente modo di apprezzare così, per lo meno a Cattaro, il nuovo corso impresso all'architettura sacra fra le due sponde adriatiche. Il seme del rinnovamento artistico germogliò anche in questo modo, raggiungendo le diocesi latine più lontane, pienamente inserite nel panorama culturale di quei secoli e segnando una volta di più il loro orientamento culturale ${ }^{40}$, ma ebbe facilità ad incanalarsi anche in territori marginali ed interni quali l'Arbanon. L'evidente mobilità dei religiosi e con loro di taluni magistri, richiamati anche su itinerari secondari e impervi, aveva il fine di esportare e replicare all'occorrenza, in forme più sobrie o rustiche, scelti e insigni modelli per distinguere e nobilitare il cantiere, enfatizzandone l'unicità e forse una pretesa supremazia o indipendenza.

La storiografia ${ }^{41}$ ha riconosciuto l'abbazia albanese di S. Salvatore nell'omonima chiesa parrocchiale, già francescana, nella cittadina di Rubik, nel distretto di Lezha e storicamente inserita in questa diocesi, ma oggi inclusa nella più giovane sede vescovile di Rreshen. In documenti tardi l'edificio è nominato con il toponimo italiano de Rebico, de Robico o de Rubico ${ }^{42}$. La continuità di frequentazione del sito ha visto l'alternarsi dai Benedettini ai Frati Minori lì insediati già nel $1640^{43}$, fino all'istituzione della parrocchiale cittadina. Si aggiungano i fisiologici momenti di abbandono e le distruzioni, circostanze dovute alla storia d'Albania o alle calamità naturali, che spiegano la particolare stratificazione dell'attuale edificio, il quale aderisce tipologicamente ad un modello di chiesa francescana. Resti murari al livello del suolo contornano la costruzione e suggeriscono la necessità di un'approfondita indagine archeologica.

31 D. FARLATI, op. cit., (n. 14), p. 427.

${ }^{32}$ J. M. MARTIN, op. cit., (n. 17).

${ }_{33}$ Ibidem. F. SFORZA, Bari e Kotor, Cassano Murge 1975. G. FEDALTO, Sulla dipendenza del vescovo di Cattaro dall'archivescovo di Bari nei secoli XI e XII, in Rivista di storia della chiesa Italiana, 30, 1976, pp. 73-80.

${ }^{34}$ N. CILENTO, I rapporti del 'Comune Pugliese' con le città delle due sponde adriatiche negli studi di Francesco Carabellese, in Archivio Storico Pugliese 34, 1981, pp. 41-53. Più in generale sul commercio fra Italia e Dalmatia cfr. G. YVER, Le commerce et les marchands dans l'Italie méridionale au XIII et XIVe siècle, Paris, 1902. M. POPOVIĆ-RADENKOVIĆ, Le relazioni commerciali fra Dubrovnik (Ragusa) e la Puglia nel periodo angioino (1266-1442), in Archivio Storico per le Province Napoletane, 76, 1958, e 77, 1959, pp. 73-104 e pp. 153-206.

${ }^{35}$ S. ĆURČIĆ, Architecture in the Balkans. From Diocletian to Süleyman the Magnificent, New Haven and London 2010, p. 452.

${ }^{36}$ G. CIOFFARI, The Tsars of Serbia and the Basilica of St. Nicholas in Bari, in Nicolaus, 1, 1981, pp. 145-175. G. CIOFFARI, Gli zar di Serbia, la Puglia e S. Nicola. Una storia di santità e di violenza, Bari 1989. M. S. CALÒ MARIANI, Architettura e arti figurative: dall'età deli Angioini all'età di Bona Sforza. La Basilica di San Nicola in età protoangioina: San Nicola e la Serbia, in G. MUSCA - F. TATEO (dir.), Storia di Bari. Dalla conquista normanna al ducato sforzesco, Roma-Bari 1990, pp. 390-404. M. BACCI, San Nicola. Il grande Taumaturgo. Roma - Bari 2009, pp. 153-156. In generale si guardi ai saggi ed al catalogo della Mostra a cura di M. BACCI, San Nicola. Splendori d'arte d'Oriente e d'Occidente, (Bari, Castello Svevo, 7 dicembre 2006 - 6 maggio 2007 ) Milano 2006.

${ }^{37}$ I. STEVOVIĆ, Byzantium, Byzantine Italy and cities on the eastern coast of the Adriatic: The case of Kotor and Dubrovnik, in Zbornik radova Vizantoloskog instituta, 39, 2001, pp. 165-182.

${ }^{38}$ Difatti si presentava con una facciata rinserrata fra torri, tipica configurazione normanna, ma il corpo longitudinale era cupolato, richiamando la tradizione bizantina, mentre internamente volte a crociera costolonate ampliavano lo spettro dei contatti fino all'area padana. S. ĆURČIĆ, op. cit. (n. 35), pp. 455-456.

${ }^{39}$ D. FARLATI, op. cit., (n. 14), p. 433.

${ }^{40}$ Sull'aggancio culturale che lega riforma ecclesiastica e cultura artistica, anche se particolarmente in area croata, cfr. M. JURKOVIĆ - N. MARAKOVIĆ, La nascita del primo romanico in Croazia nel contesto delle grandi riforme ecclesiastiche del secolo XI, in A. CALZONA, R. CAMPARI, M. MUSINI (dir.), Immagine e ideologia. Studi in onore di Arturo Carlo Quintavalle, Milano 2007, pp. 96-102.

${ }^{41}$ A. DUCELLIER, op. cit. (n. 5), pp. 178-179, T. IPPEN, Shquipëria e vjetër [Albania antica], Tiranë 2002. A. MEKSI, op. cit. (n. 24), pp. 146-147. G. HOXHA, L. PËRZITA, F. CAVALLINI F., Monumenti storici di culto cristiano della Diocesi di Lezha, Lezhë 2007, pp. 139-146.

${ }^{42} \mathrm{~V}$. infra, nota 43, e pp. sgg.

${ }^{43}$ Da una relazione di Fra Marco Scura, arcivescovo di Croia, fatta a seguito di una Santa Visita intorno al 1640 si apprende che: "[...] Santo Saluatore di Veglia, Santo Salvatore di Rubico ambidua Conventi de PP. Minori Osseruanti, Robico anticamente Abbatia [...]. In F. CORDIGNANO, op. cit. (n. 12), p. 257. 


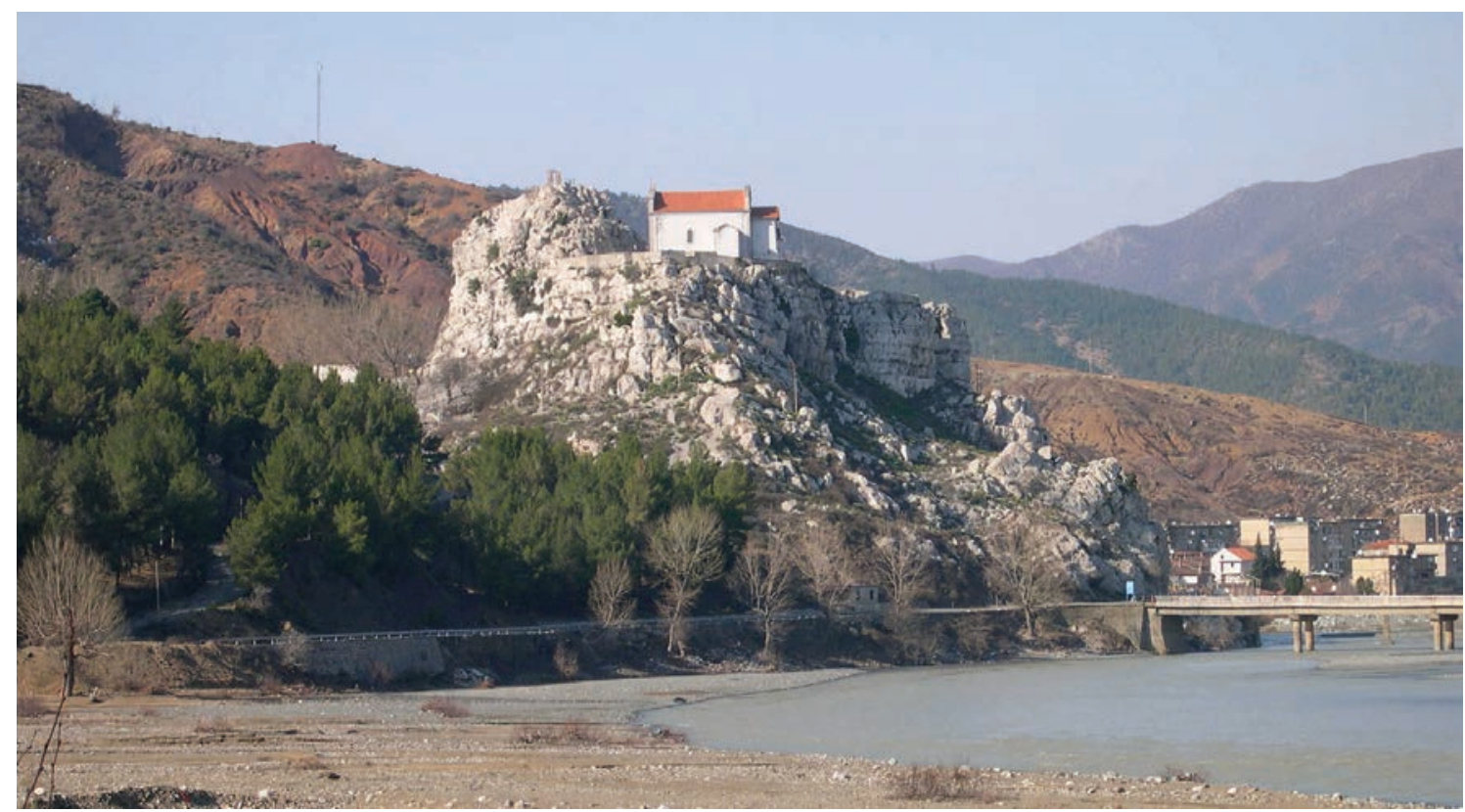

Fig. 2. Rubik, chiesa del Salvatore.

La fondazione benedettina medievale si avvantaggiava di una posizione favorevole, su uno sperone roccioso a picco di un'ansa del fiume Fan (fig. 2), avendo così facilità di approvvigionamento idrico e soprattutto potendo controllare da posizione eminente quell'itinerario terraqueo che costeggiava o sfruttava il fiume, collegando la costa con l'Arbanon fino alle alture di Orosh dove sorgeva un'altra abbazia detta di S. Alessandro in Monte, ma anche ricongiungendosi con l'Itinerarium Lissus-Naissus ${ }^{44}$. Rassicurante signaculum per coloro i quali per i più disparati motivi viaggiavano su quel percorso a piedi o avvalendosi della navigazione fluviale.

L'attuale chiesa del Salvatore di Rubik è il frutto di radicali fasi ricostruttive e di restauro che da fine XIX secolo ai primissimi anni di questo millennio ne hanno completamente cambiato l'aspetto originario, ma anche permesso la sopravvivenza delle poche e riconoscibili fasi medievali integrate nel nuovo edificio ${ }^{45}$. La classicheggiante facciata in pietra grigia accoglie un unico portale ed è ingentilita da quattro lesene nell'ordine inferiore. Una cornice marcapiano separa il timpano triangolare e s'inarca al centro per abbracciare il rosone.

L'impianto dell'edificio propone la tipologia ad aula unica, con basso transetto sporgente e coro quadrangolare, replicando deliberatamente la chiesa francescana di Scutari $^{46}$. L'unica anomalia risulta essere l'antica abside medievale che fuoriesce dalla parete orientale del coro, ben individuabile anche a distanza per le sue sobrie forme romaniche riecheggianti più noti e monumentali prototipi. Alcune foto storiche, antecedenti i restauri del secolo scorso (fig. 3), mostrano come l'articolazione ad archetti intrecciati,

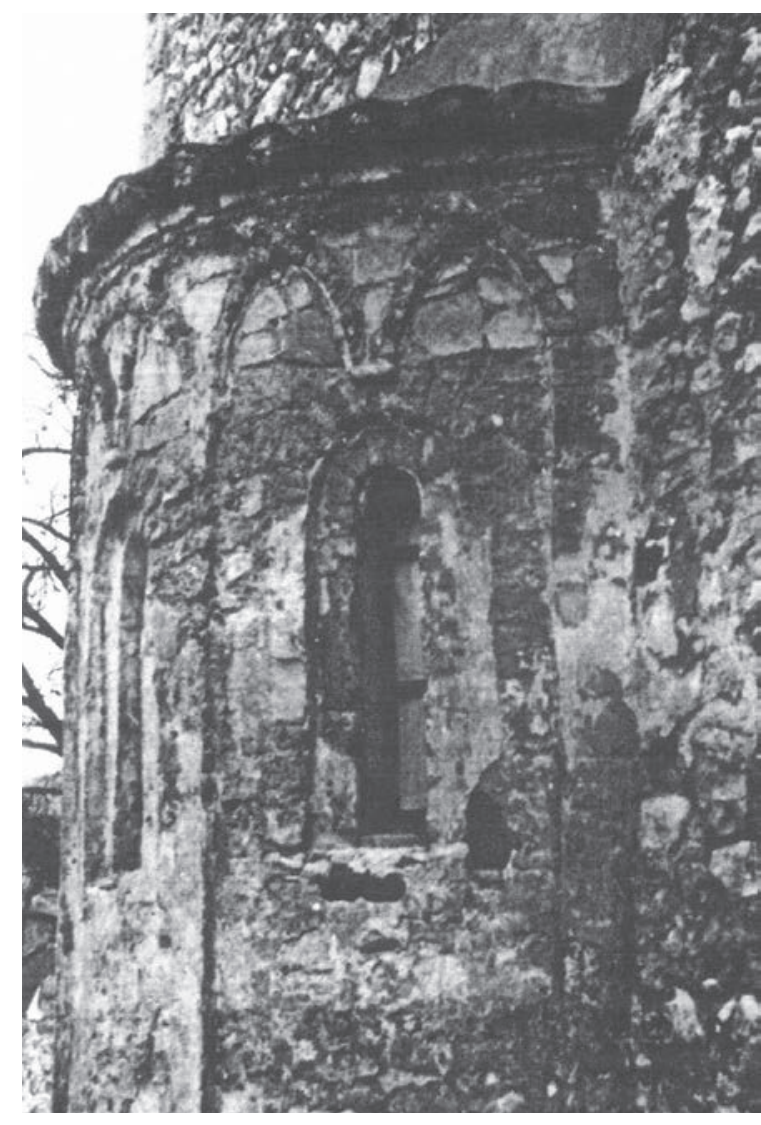

Fig. 3. Rubik, chiesa del Salvatore, particolare dell'abside prima dei restauri (da A. Meksi, 2004).

${ }_{44}$ In un mio precedente studio ipotizzo l'esistenza di un fenomeno di pellegrinaggio sulla direttrice che collega la costa con l'interno della Mirdita, passando per Rubik e concludendosi presso la chiesa di S. Alessandro di Orosh, utilizzando un diverticulum dell'Itinerarium Lissus-Naissus, cfr. G. CAMPOBASSO, Testimonianze di culto iacopeo e cateriniano in Albania ed una poco nota direttrice di pellegrinaggio: la chiesa di Shën Barbullës (S. Barbara) a Pllanë, in Ad limina. Revista de investigación del Camino de Santiago y las peregrinaciones, 3, 2012, pp. 43-71, in partic. p. 70. Il trapianto del culto di S. Alessandro protomartire romano segna anche per l'Arbanon uno stretto legame con la città pontificia, la cui introduzione risale ad un'epoca imprecisata. Per lo studio del culto e dell'omonima abbazia scarseggiano tuttora le fonti. Il monastero, ricordato come abbatia nullius, era retto da un abate mitrato (lo stesso effigiato nella Deesis di Rubik ??) che aveva prerogative vescovili sulla Mirdita, difatti l'insediamento è citato anche come Abbazia della Mirdita, avendo possedimenti ed influenza sulla regione fra il Drin ed il Mati. Sembra vi si custodisse in una preziosa teca, chiamata "Arka e Shêitit", la testa del santo militare, e fra le reliquie e gli oggetti d'arte suntuaria del tesoro si ricordano un frammento della Vera Croce, in una stauroteca argentea, e due croci processionali del XV secolo. Tali manufatti sono andati dispersi nel tempo, saccheggiati dai turchi o perduti nell'incendio del 1895 che distrusse il monastero, poi ricostruito più a valle vicino al centro abitato. F. CORDIGNANO, Antichi monasteri benedettini in Albania nella tradizione... op. cit. (n. 24), in partic. pp. 507-513. F. CORDIGNANO, op. cit. (n. 12 ), p. 258. ${ }^{45}$ ADHAMI S., Shtjefën Gjeçovi një ndër pionierët e mbrojtjes dhe gjurmimit të monumenteve (riass. Shtjefën Gjeçovi l'un des pionniers de la protection et de la recherche des monuments) in Monumentet, 2, 1981, pp. 91-97. G. HOXHA, L. PËRZITA, F. CAVALLINI F., op. cit. (n. 41). 


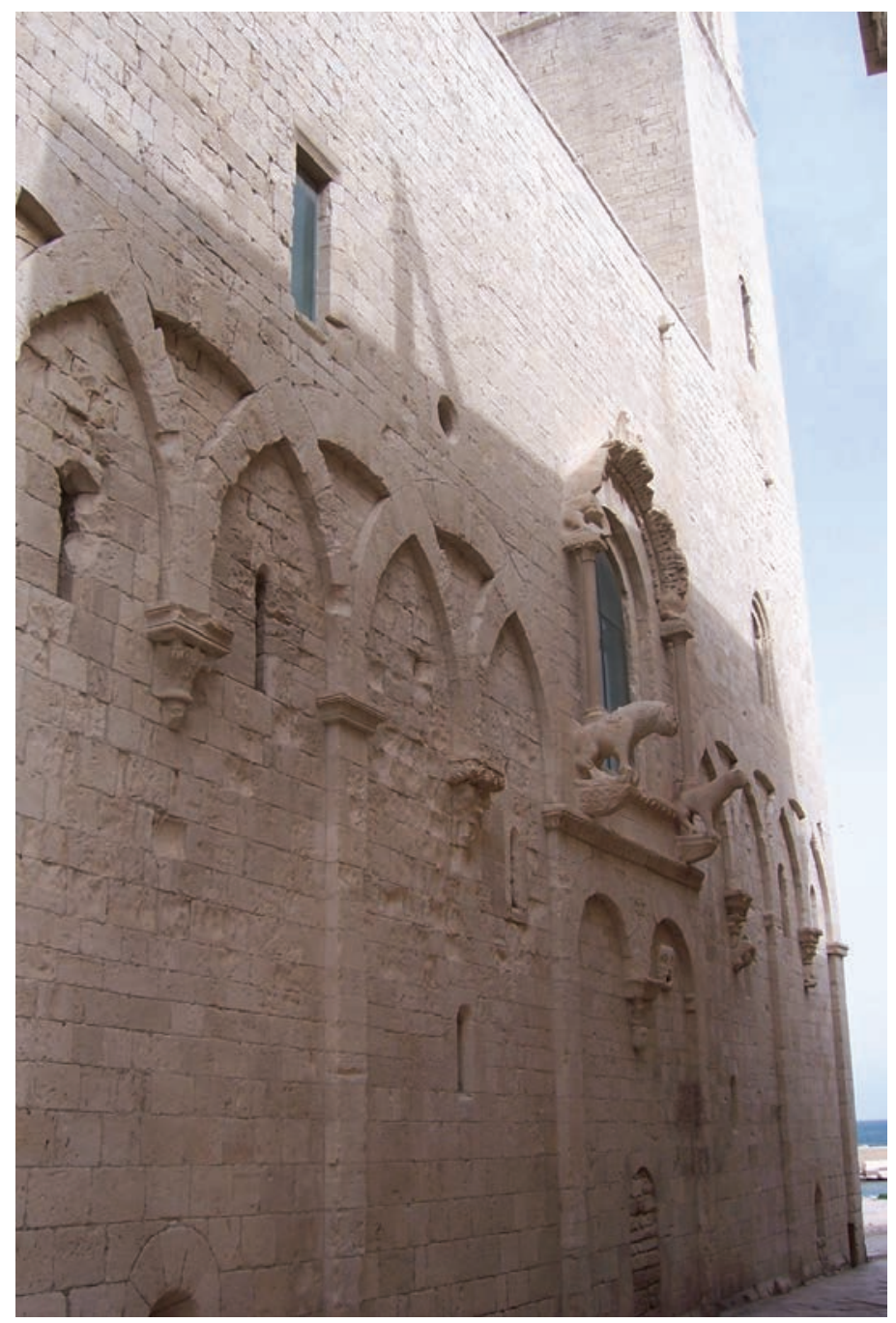

Fig. 4. Molfetta, cattedrale di S. Corrado, parete absidale.

con il ricorso ad una ritmica zoppa che alterna imposte pensili a lesene, sia originaria. Questo tipo di decorazione architettonica in forme ben più ricche e monumentali fu una soluzione di largo uso a partire dai cantieri reali della Sicilia, ereditata dalla cultura islamica ${ }^{47}$. Divenne parte della tradizione costruttiva normanna, diffondendosi anche nell'arco tirrenico e in seguito in area adriatica, comparendo nel nord della Terra di Bari fra tardo XII secolo e XIII, nelle cattedrali di Giovinazzo e Molfetta. Quest'ultimo cantiere, dedicato a S. Corrado e avviato nel 1185 , ma prolungatosi per tutto il secolo successivo ${ }^{48}$, propone una scansione alternata fra lesene e peducci pensili a decoro dell'intera parete absidale rettilinea (fig. 4), ma rispettando la soluzione planimetrica delle tre absidi incassate nella muratura elaborata per la basilica nicolaiana barese, insigne riferimento architettonico in quell'area. Proprio l'attardarsi di questo modulo decorativo romanico in età sveva e fino alle soglie dell'età angioina nel meridione d'Italia, rende fluttuante una datazione per l'abside di Rubik. Il monastero medievale nel XIII secolo fu oggetto di un attacco apportato da milizie sveve sulla sponda albanese $^{49}$, nel quadro di un'espansione di Manfredi, figlio del defunto imperatore Federico II, e della continua rivalità di questi con la chiesa di Roma che mirava a delegittimare la sua stirpe sovrana. Le truppe dello Staufen, comandate da Andrea Vrana, capitano d'Albania ${ }^{50}$, attaccarono il monastero forse per ritorsione proprio verso il papato. Questo avvenimento è filtrato da un'iscrizione epigrafica conservata nella chiesa almeno fino al XVII secolo. La copiò, purtroppo non senza errori, il vescovo di Lezha Benedetto Orsini nel 1629 durante una Santa Visita annotando ${ }^{51}:$ «S. Saluatore di Rebico; fu Badia à tempi antichi come da questa inscrittione appare, che si uede sopra la porta della Chiesa di sotto, che dice cosi:

\section{ANNO D.NI N.RI IESU CHRISTI 1267. INDITIONE NONA / \\ RESIDENTE IN S.TA ET AP.LICA SEDE N.RO IMPERA- TORE CONSTANTINOPOLI / \\ MICHAELE PALEOLOGO / \\ CAP(I)T(ANEUS) ARBAN(I) CMIBRI [?] ${ }^{52}$ \\ ID E. ANDREAS VRANA VENIES DESTRUXIT ISTAM ECCLESIAM, / \\ REX MANFREDO DOMINAUIT DIRACHIUM».}

All'interno di quell'abside, un ciclo affrescato che una volta si distendeva su tutta la parete orientale, ha fra i suoi brani meglio conservati quello nella conca absidale dove campeggia una Deesis con donatore ed epigrafe dedicatoria. Ad oggi molto scolorita, ma ancora in parte leggibile, ne possediamo una trascrizione tramandata dalla storiografia locale ${ }^{33}$. Il testo datato ad annum dice così:

\section{PROTEGE D[OMI]NE [I]N[DIGN]UM FAMUL[UM] TE ABATI INOCENTI / CUM ON[IBUS] FRAT[I] B[US]: ECLESIE. ANI D[OMI] NI MCCLXXII}

La cronologia fornisce un terminus ante quem, non solo per le pitture, ma plausibilmente per l'intera ricostruzione dell'edificio dopo che fu distrutto dalle milizie sveve pochi anni prima. Nonostante ciò rimane difficile esprimersi su una datazione più precisa per la struttura muraria che fu

\footnotetext{
${ }^{46}$ G. HOXHA, L. PËRZITA, F. CAVALLINI F., op. cit. (n. 41).
}

47 U. SCERRATO, L'architettura, in F. GABRIELI - U. SCERRATO (dir.), Gli Arabi in Italia, Milano 1985, pp. 307-398. W. TRONZO, The artistic culture of twelfth-century Sicily, with a focus on Palermo, in C. KARAGOZ - G SUMMERFIELD (eds.), Sicily and the Mediterranean. Migration, exchange, reinvention, London 2015, 61-76. Per il problema del primo sviluppo in Campania di questo motivo, giuntovi probabilmente dalla Spagna islamica per il tramite normanno, cfr. BOTTARI S., I rapporti tra l'architettura siciliana e quella campana nel Medioevo, in Palladio, V, 1955, pp. 7-28.

${ }^{8}$ P. BELLI D’ELIA, Puglia Romanica, Milano 2003, pp. 199-211.

49 Fra il 1258 e l'anno della sua morte, nel 1266, Manfredi fu impegnato nell'allargare i suoi feudi oltremare tanto con campagne militari, che perseguendo una politica matrimoniale. Difatti prese in moglie la principessa Elena d'Epiro ricevendo la conferma di tutte le sue conquiste sul litorale albanese, anzi ampliandole con la dote che comprendeva postazioni sulla costa epirota. P. XHUFI, op. cit. (n. 7).

${ }^{5}$ Ibidem. A. DUCELLIER, op. cit. (n. 5), pp. 178-179.

${ }^{51}$ F. CORDIGNANO, op. cit. (n. 12), p. 244

${ }^{52}$ Questa formula è stata sciolta come "Capitaneus Arbani et Dyrrachii” identificando nella parola cmibri un errore di trascrizione al posto della parola Dyrrachii. P. XHUFI . op. cit. (n.7). G. HOXHA, L. PËRZITA, F. CAVALLINI F., op. cit. (n. 41).

53 T. IPPEN, op. cit. (n. 41). D. DHAMO, Piktura e vjetër murale e kishës së Rubikut dhe datimi i saj i ri [Le pitture di un'antica parete della chiesa di Rubik e la loro nuova datazione], in Studimi Historike, 2, 1964, pp. 87-94; G. HOXHA, L. PËRZITA, F. CAVALLINI F., op. cit. (n. 41). 


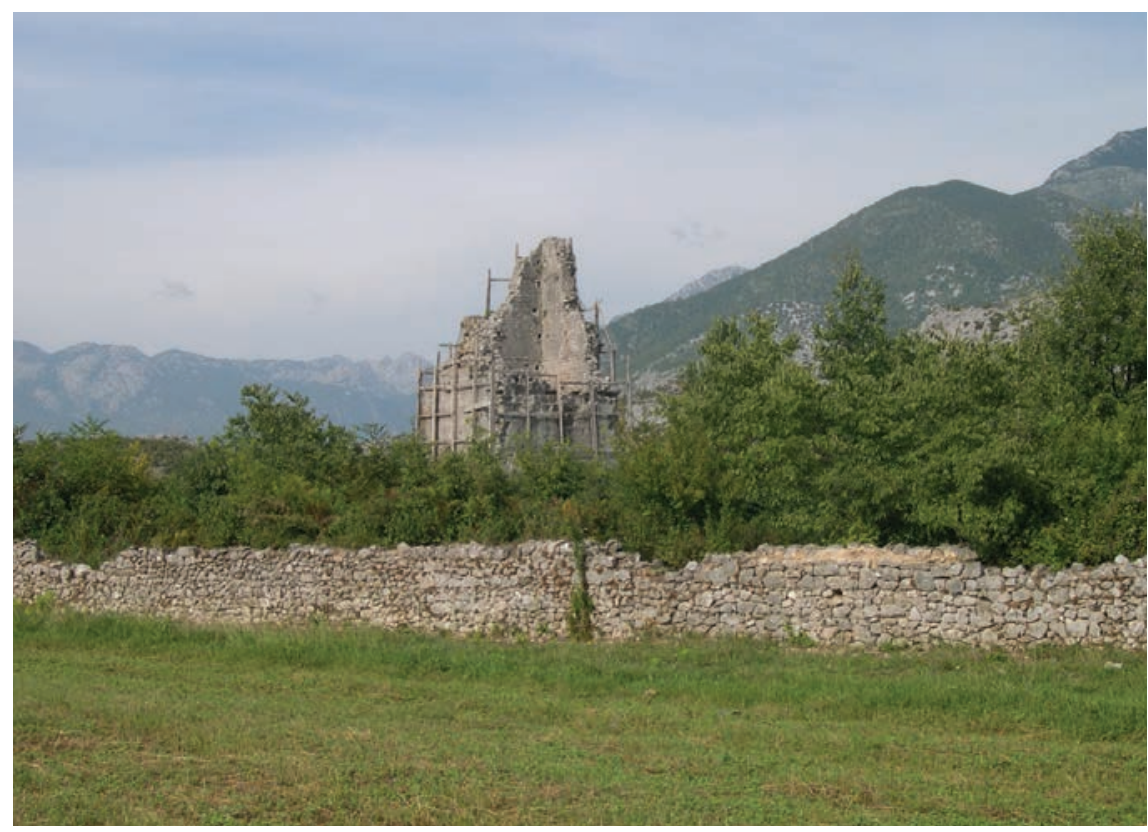

Fig. 5. Boriq, rovine del monastero di S. Giovanni.
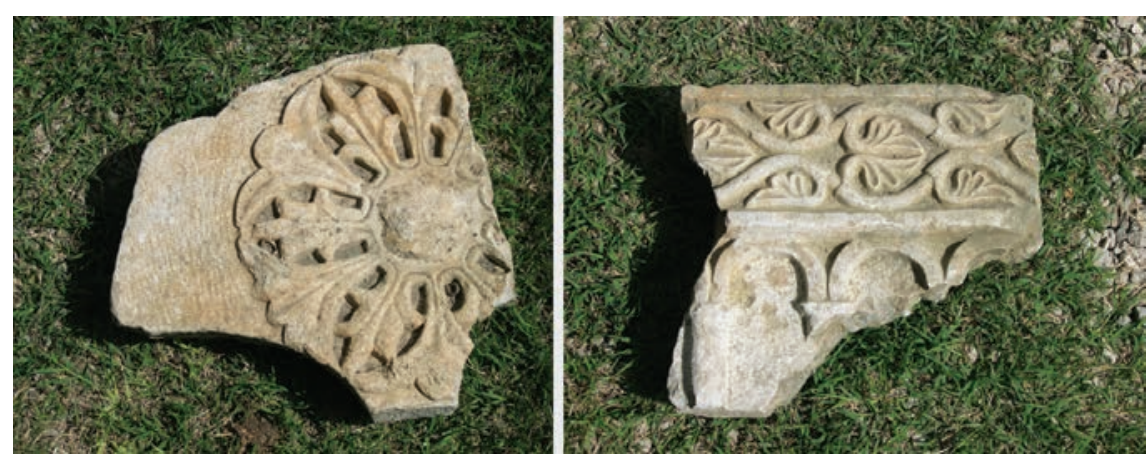

Fig. 6. a-b. Boriq, monastero di S. Giovanni, frammenti erratici.

elevata fra il secondo XII secolo e la ricostruzione del 1272. Quell'anno, successivo alla presa di Durazzo da parte della flotta di Carlo d'Angiò, fu promulgato il primo documento in cui il sovrano reca anche il titolo di rex Albanie ${ }^{54}$. La Deesis conserva ai piedi della figura del Cristo in Maestà, un cuscino suppedaneo decorato a losanghe e fleurs de lis, un'associazione molto comune nell'arte protoangioina che abbina figure sacre e regali al giglio capetingio, simbolo cosmico e divino, ma anche d'intermediazione fra la sfera sensibile ed il mondo celeste, che amplifica la funzione messianica e sacrale dei sovrani francesi ${ }^{55}$. Il ciclo conserva nei livelli inferiori una Comunione degli Apostoli e, più in basso, una schiera di sette santi concelebranti con al centro la figura di papa Silvestro I, già caricato di significati antisvevi negli affreschi della cappella a lui dedicata presso la basilica romana dei Santi Quattro Coronati, datata pochi decenni prima ${ }^{56}$. Tutto il ciclo allude alla vittoria della Chiesa di Roma e del "glorieux bras et champion de la sainte Eglise, Charles" ${ }^{57}$ sul partito svevo, e la ricostruzione stessa del monastero assume significato nella propaganda filoangioina in Albania.

All'esterno di quella parete, l'apparecchio murario si distingue dalla più comune tecnica costruttiva di ambito benedettino, la quale di norma predilige pietra da taglio ben sagomata e messa in opera in filari regolari. È il caso del complesso monastico di S. Giovanni di Boriq, sulla sponda orientale del Lago di Scutari e in territorio di Shtoi, dove la precisa squadratura dei conci ordinatamente posati è ancora ben evidente nella possente torre a difesa di quello che fu un insediamento fortificato, oggi in grave stato di rovina (fig. 5). La perizia espressa nella tessitura muraria ed i frammenti dell'apparato scultoreo sparsi nei dintorni segnalano l'adesione ad un milieu benedettino. Il crollo parziale della torre, pressoché totale nel caso della chiesa, permettono di distinguere come le pareti fossero elevate "a sacco". Mentre il frammento di una bifora ornata con un rilievo piatto e grafico di una rosa spinosa suggerisce paralleli nella scultura d'ambito monastico fra XII e XIII secolo, o il motivo ad archetti continui che regge una cornicetta con un nastro fogliato (fig. 6 a-b). L'effetto d'insieme, anche per la similarità del paesaggio in cui s'inscrive, rende esplicito il gioco dei rimandi con la costa italiana fra quei secoli, specialmente con l'area garganica dove il monastero benedettino della SS. Trinità di Montesacro presso Mattinata riserva parallelismi nel magistero murario, nelle forme architettoniche e nella configurazione fortificata. Mentre la chiesa di S. Maria di Càlena a Peschici, appartenuta a quell'Ordine, e quella cistercense di S. Maria di Ripalta a Lesina, mettono in mostra un patrimonio di ornati vegetali che, tanto nelle forme quanto nei modi stilistici (figg. 7-8), trova strette affinità con i frammenti scultorei di Boriq. Un'adesione a modelli insediativi e di tecniche e forme, concepibile solo con lo stretto scambio di maestranze ed esperienze da cantiere a cantiere.

Eppure a Rubik la muratura, pur evidenziando almeno due fasi, differisce per l'uso di pietrame, con conci di pezzatura varia (fig. 3), denotando come l'adesione ad una cultura comune di riferimento potesse anche essere parziale, mitigata dalla tradizione locale. Una fase sembra corrispondere all'intero giro di archetti e nonostante l'ordito rustico, questo non ha impedito il ricorso al più elegante e nobile motivo decorativo dell'intreccio, il quale circolava nel Mediterraneo,

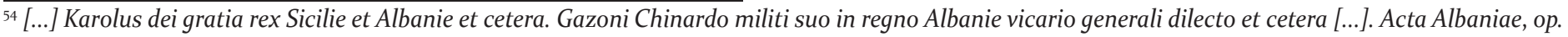
cit. (n. 14), vol. 1, doc. 270.

55 La composizione araldica del seminato di gigli in campo azzurro, diviene metafora del cosmo: un cielo stellato che specifica l'universalità del potere dei monarchi francesi. M. PASTOUREAU, Bleu. Histoire d'une couleur, s.l. 20o6. Ancora: ID., Un fiore per il re. Per una storia medievale del Giglio di Francia, in ID., Medioevo simbolico, Roma-Bari 2007, pp. 87-98. Per un'analisi approfondita delle pitture v. G. CAMPOBASSO, op. cit. (n. 3).

${ }^{56} \mathrm{~J}$. MITCHELL, St. Silvester and Constantine at the Ss. Quattro Coronati, in A. M. ROMANINI (a cura di), Federico II e l'arte del Duecento italiano, atti della III settimana di Storia dell'arte medievale dell'Università di Roma, Galatina 1980, vol. II, pp. 15-32; A. TOMEI, Storie di S. Silvestro, in Laboratorio di restauro, catalogo della mostra (Roma, 14 dicembre 1985-28 febbraio 1986), Roma 1985, pp. 160-3; F. GANDOLFO, Aggiornamento scientifico e bibliografia, in G. MATTHIAE, Pittura romana del medioevo. Secoli XI-XIV, Roma 1988, p. 300; A. IACOBINI, La pittura e le arti suntuarie: da Innocenzo III a Innocenzo IV (1198-1254), in A. M. ROMANINI, Roma nel Duecento. L'arte nella città dei papi da Innocenzo III a Bonifacio VIII, Torino 1991, pp. 237-419, in part. pp. 282-3. 57 In questo modo il domenicano Gilles d'Orléans invitava a pregare per l'angioino nella cappella del re di Francia. J. P. BOYER, op. cit. (n. 22).
} 


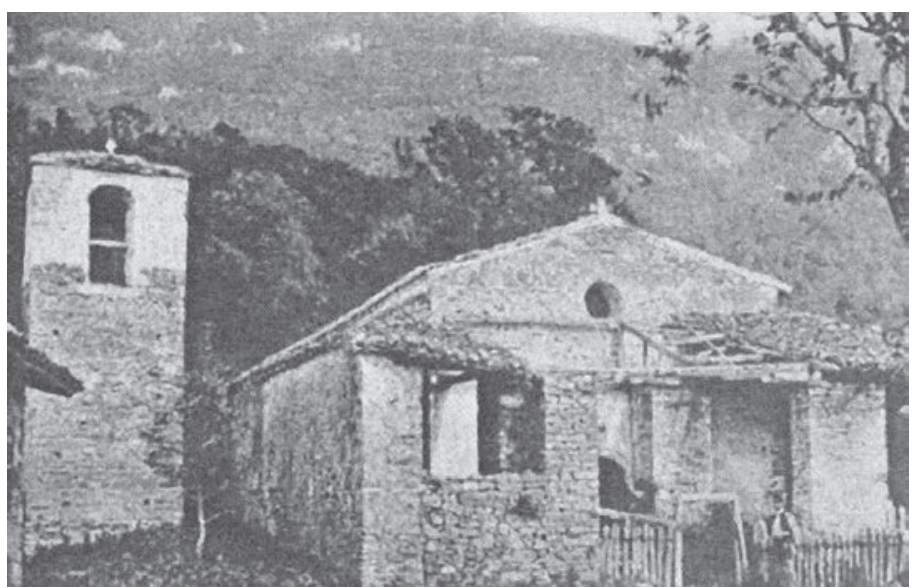

Fig. 9. Kurbin, chiesa di S. Veneranda a fine XIX secolo (da K. Marku, 2008)

unificando le sponde nordafricana e iberica, musulmane, con il Mezzogiorno italiano ed ora anche i Balcani fra XII e XIII secolo. Le maestranze specializzate di lapicidi, attive presso i principali cantieri cittadini o abbaziali, muovendosi lungo i canali dei contatti religiosi, erano in grado di esportare e diffondere modelli di successo, adattandoli alla tradizione costruttiva locale. Lo schema decorativo in questione, a Rubik potrebbe essere stato scelto per meglio rimarcare la supremazia e l'importanza di questo insediamento come abbazia dell'Arbanon, e alla luce di una situazione politico-culturale che sempre più ricuciva le distanze fra le due sponde meridionali dell'Adriatico.

Un parallelo tutto albanese è però offerto dalla chiesa di S. Veneranda di Kurbin, pochi chilometri a sud di Rubik e non longe ab Croja in pago $^{5}$. Una foto storica di fine XIX secolo mostra, per quanto malamente, una teoria di archetti intrecciati pensili inclusi nella muratura del campanile (fig. 9). Ancora oggi è possibile individuarne i resti nonostante lo stato di rovina della torre campanaria come di tutto il complesso. Il Cordignano ricorda un'abbazia di S. Veneranda di Curbino ${ }^{59}$, attestata anche da recenti ricerche ${ }^{60}$, mentre notizie più circostanziate fanno riferimento anche qui ad un avvicendamento tardo dei Francescani ${ }^{61}$. Gli Ordini Mendicanti ed in particolare i Frati Minori, iniziarono ad espan-

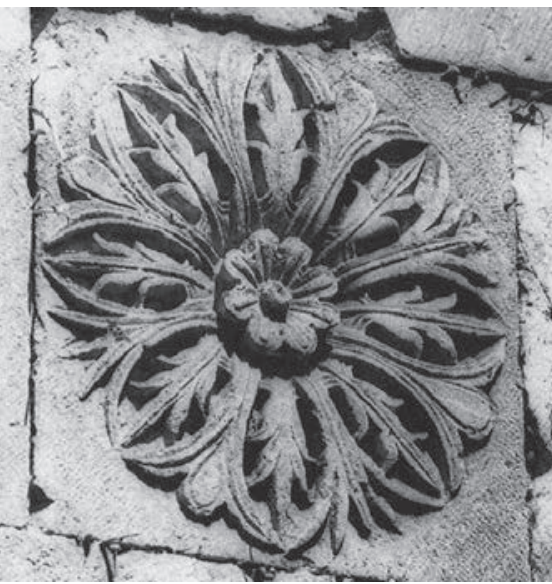

Fig. 7. Peschici, chiesa di S. Maria di Càlena, rosetta spinosa (da M.S. Calò Mariani, 1984).

dersi in Albania alla metà del XIII secolo. Nel 1248 è documentata l'introduzione di una comunità di frati a Durazzo proveniente da Antivari, guidata da Francesco da Pian del Carpine ${ }^{62}$. Lo stesso impianto della chiesa di S. Veneranda di Curbino, per quanto oggi allo stato di rudere, risponde alla diffusa tipologia mendicante ad aula unica, priva di transetto e con coro quadrangolare, presumibilmente un tempo voltato ${ }^{63}$. Nonostante la rovina, le creste murarie rimaste ne disegnano la planimetria, ed è altrettanto evidente l'uso di un

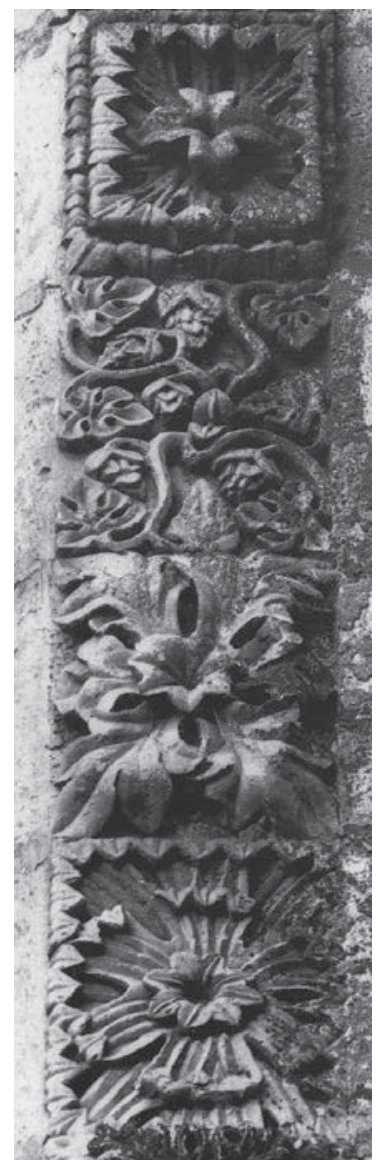

Fig. 8. Lesina, chiesa di S. Maria di Ripalta, formelle a decorazione vegetale (da M.S.

Calò Mariani, 1984). ordito rustico in pietrame misto, congruente con la cultura edilizia francescana.

È ipotizzabile che la successione fra i due ordini religiosi, frequente e documentata per molti insediamenti nell'Albania cattolica, fra tardo medioevo e prima età moderna ${ }^{64}$, abbia portato al riutilizzo di talune parti del complesso nonostante la ricostruzione e l'adesione ad un'icnografia

$5^{8}$ D. FARLATI, Ecclesia Diocletana, Antibarensis, Dyrrhachiensis, et Sirmiensis, in Illyricum Sacrum, tomo 7 $7^{\circ}$, Venezia 1817, p. 205.

${ }^{59} \mathrm{~F}$. CORDIGNANO, Antichi monasteri benedettini in Albania nella tradizione... op. cit., in partic. pp. 505- 506.

${ }^{60} \mathrm{G}$. CAMPOBASSO, Testimonianze di architettura sacra net territorio fra Krujë e Lezhë, in A. PEPE, (dir.) Itinerari di arte e devozione fra Albania e Puglia, Bari 2008, pp. 6-7. Ma soprattutto K. MARKU, Kishat e Kurbinit, Tiranë 2008.

${ }^{61}$ La presenza dei Francescani presso quell'insediamento è documentata almeno dal XVII secolo da Fra Marco Scura di Croja, Arcivescovo. Nella relazione di una Santa Visita del 1640 l'alto prelato riporta come, successivamente alla occupazione turca della città di Krujë nel 1478 e alla distruzione della cattedrale, le sedi diocesane d'Albania vennero accorpate e si ordinò un solo arcivescovo detto Albanense. Questi, causa la grave instabilità dell'epoca, non aveva una sede vescovile fissa e per certi periodi risedette anche nella chiesa di $S$. Veneranda di Corbino "[...] coi PP. di S. Francesco e 2 sacerdoti [...]". Per tali ragioni la chiesa è indicata anche come "[...] Chiesa cattedrale di Corbino sotto il titolo di S. Veneranda, antica Abbazia [...]. F. CORDIGNANO, op. cit. (n. 12), pp. 255-256.

${ }^{62}$ A. DUCELLIER, op. cit. (n. 5), pp. 208-209.

${ }^{63}$ Questa tipologia di edificio è adottata dagli Ordini Mendicanti tramite i quali ebbe capillare diffusione in tutta l'Europa cattolica del XIII secolo. Trova attestazione anche in Dalmatia ed Albania, come dimostra la chiesa conventuale della SS. Annunziata, sede dei Minori Francescani di Lezha, secondo tradizione addirittura databile al 1240, cfr. G. HOXHA, L. PËRZITA, F. CAVALLINI F., op. cit. (n. 41), pp. 41-46. Questo edificio, più volte ricostruito, è oggigiorno coperto da capriate anche sul presbiterio. In epoca precedente, l'arco trionfale, crollato all'altezza dell'archivolto, permetteva di accedere ad un coro quadrangolare certamente voltato a crociera costolonata, come dimostrano le culots conservatesi agli angoli dell'ambiente. Questa soluzione, sembra ripetuta anche nella cosiddetta cattedrale di S. Stefano nella rocca di Rozafa a Scutari. Della chiesa, trasformata in moschea dopo la presa della città da parte dei turchi, rimane il coro quadrangolare con le imposte dell'arco trionfale, ed un capitello angolare. Le tre fabbriche di Curbino, Lezha e Scutari, a loro volta non sono dissimili da edifici mendicanti situati tanto sulla costa dalmata che su quella italiana A. BADURINA, Sakralna arhitektura, in Zlatno doba Dubrovnika XV i XVI stoljeće, Zagreb 1987, pp. 109-123 (riass. Ecclesiastical architecture, p. 400). Ad ulteriore riprova dell'esistenza di una circolazione artistica sulla costa balcanica che prolungò la stagione di scambi che sfruttava canali religiosi, va ricordata l'appartenenza del convento dell'Annunziata alla Custodia Cattarensis, parte della Provincia Dalmata. G. HOXHA, L. PËRZITA, F. CAVALLINI F., ibidem.

${ }^{64}$ G. FEDALTO, op. cit. (n. 8). R. ELSIE, v. ad vocem Benedectin Order, in ID, A dictionary of Albanian religion, mythology, and folk culture, London 20o1, p. 34. M. F. DI MICELI, I Francescani in Albania, in V. NOSILIA - M. SCARPA (dir.), I Francescani nella storia dei popoli balcanici, atti del Convegno Internazionale di Studi, Venezia, 13-14 novembre 2009, Venezia 2011, pp. 27-36. 


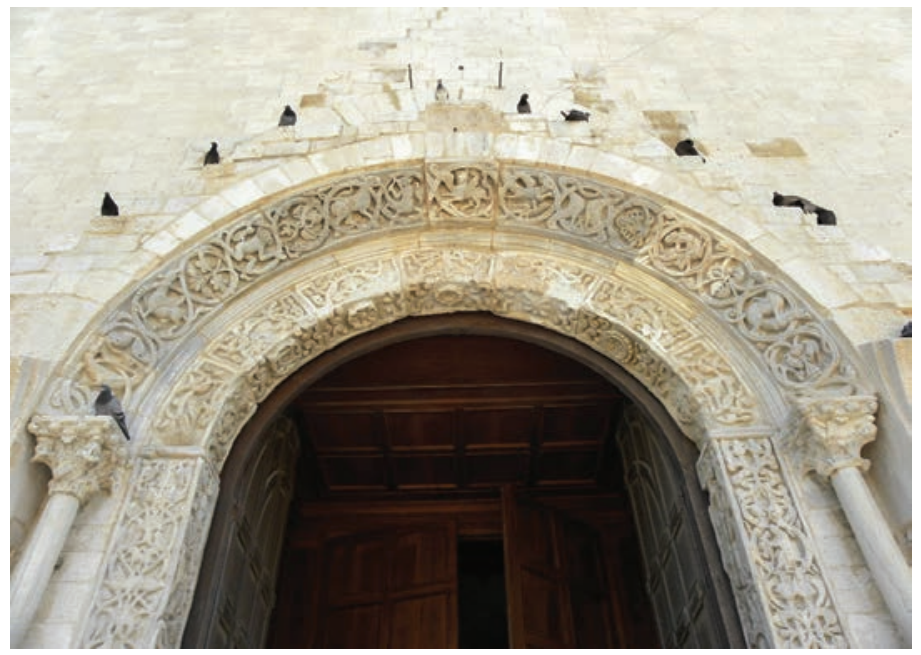

Fig. 10. Trani, cattedrale di S. Nicola Pellegrino, portale maggiore (gentile concessione dell'Archivio Fotografico Pugliese - Hic Locus Est).

minorita. Ad ogni modo, la chiesa di S. Veneranda di Curbino condivideva con Rubik l'elegante motivo decorativo ad intreccio che rimonta a quei secoli, documentando lo stretto legame con la cultura artistica italo-meridionale del secondo medioevo.

Un'altra riflessione s'impone a proposito del successo di quella o altre soluzioni mutuate dall'Occidente ed a riguardo della loro distribuzione sul territorio, la quale dovette essere certamente più capillare di quante oggi siano le testimonianze sopravvissute e note agli studi.

Tornando all'analisi dell'abside di Rubik, fra le lesene sono incastonate tre monofore prive di strombo e non decorate, ma circoscritte da una doppia cornice di conci disposti in maniera radiale, con la più interna rincassata rispetto alla muratura. Propongono una tipologia di finestratura di estrazione bizantina, comune nelle chiese di Berat e datata da Meksi fra XIII e XIV secolo, avvalorando la cronologia più tarda di tutta la struttura ${ }^{65}$ che ricorre a un proprio sincretismo fra modelli romanico-normanni, sopravvivenze bizantine e tecniche locali.

D'altro canto, l'uso di formule romaniche nel XIII secolo e ancora nel successivo, è una ben nota caratteristica dell'architettura balcanica di area serba, in parallelo con il mezzogiorno italiano dove convivenze e attardamenti, entro il nascente linguaggio gotico, sono la norma. Tali manifestazioni artistiche erano il prodotto di società miste, economicamente e culturalmente dinamiche site in "regioni di frontiera". Si pensi ancora alle fondazioni dei Nemanjić nell'entroterra serbo: queste attingevano pienamente ad un repertorio pan-adriatico, per quanto atteneva ad architet-

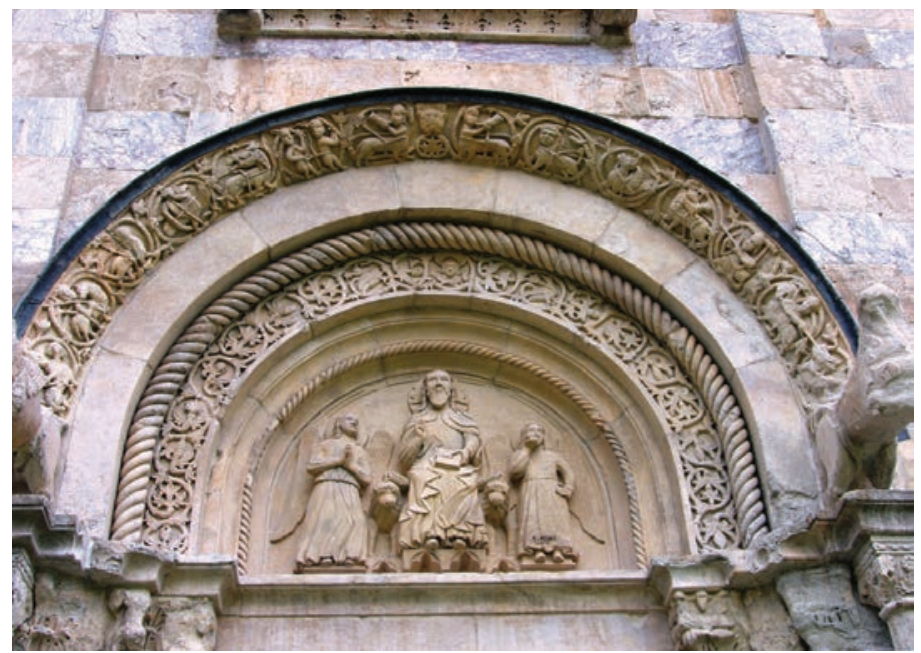

Fig. 11. Dě́ani, monastero del Cristo Pantocratore, portale maggiore del katholikon.

tura e scultura, attraverso maestranze reclutate dal litorale, con Cattaro e Ragusa come tramite fra la sponda italiana e il regno serbo. La contiguità geografica e la similitudine dei fenomeni culturali suggeriscono l'inclusione della fascia costiera albanese e dell'Arbanon in una circolazione che sembra accomunare le transperiferie adriatiche dell'Impero bizantino ${ }^{66}$. Calate nei commerci adriatici, variamente orientate verso Oriente o Occidente dalla religione o dalle convenienze politiche e economiche, oppure dalle ingerenze dei dominatori che vi si alternavano, queste regioni non furono estranee alle interazioni fra differenti linguaggi artistici.

Non si può escludere l'Albania dal transfer documentato con il trapianto di maestranze pugliesi sulla costa dalmata meridionale nell'ultimo scorcio del XII secolo. Alcuni dei cosiddetti magistri tranesi, attratti dal rinnovamento delle fabbriche cattedralizie d'oltreadriatico, furono richiamati dalla città pugliese a Ragusa. Il caso noto dalle fonti e analizzato da tanta letteratura ${ }^{67}$ non dovette essere l'unico, anzi è indicativo di una dinamica comune a tutta quella fascia costiera che, per carenza di documenti scritti, ci impone di interrogare le restanti testimonianze monumentali.

I patti commerciali stipulati fra le città frontaliere dell'Adriatico provano poi la regolare frequenza dei contatti ultramarini, e la facilità e rapidità di movimento e comunicazione, spiegando la diffusione di attivi nuclei di forestieri nei principali porti. Per tali ragioni fu certamente naturale per Eustasius e suo padre, il protomagister Bernardus, dopo essere stati i raffinati artefici del portale della cattedrale di Trani fra il 1175 ed il 119o (fig. 10), trovare lavoro successivamente nella cattedrale ragusina, come ricorda un documento del 1199

${ }_{65}$ L'architetto albanese Aleksandër Meksi aggancia l'abside di Rubik al XII secolo, ma quello di Rubik è un modulo plausibile ancora nel XIII secolo, coerente con l'attardarsi di formule romaniche nei Balcani fino al secolo seguente, fenomeno ravvisabile anche nelle fondazioni albanesi di cui si tiene conto in questo articolo. Meksi inoltre, data similari tipologie di finestratura, riconosciute in alcune chiese bizantine proprio al XIII-XIV secolo. A. MEKSI, op. cit. (n. 24), pp. 102-104; 110-112; 146-147.

${ }^{66}$ Questo termine, mutuato dagli studi storici, è applicato per la prima volta alla storia dell'arte da V. PACE, La transperiferia bizantina nell'Italia meridionale del XIII secolo. Affreschi in chiese del Salento pugliese, della Basilicata e della Calabria, in J. P. CAILLET - F. JOUBERT (dir.), Orient et Occident méditerranéens au XIII siècle: les programmes picturaux, atti del Colloquio Internazionale organizzato dall'École Française d'Athènes (Athènes, 2-4 aprile 200o), Paris 2012, pp. 215-234. Esso denota una produzione artistica ibridata da parte di quelle province una volta parte dell'impero bizantino, ma ormai avviate all'interno di processi socio-culturali di stampo occidentale.

${ }^{67}$ C. FISKOVIĆ, Fragments du style roman à Dubrovnik, in Archeologia jugoslavica, 1, 1954, pp. 117-137. ID., Prvi poznati dubrovački graditelji, Dubrovnik 1955, pp. 23-29. ID., Contributions sur le relations artistiques entre Dubrovnik et la Dalmatie d'une part et l'Apulie de l'autre, in Zbornik za likovne, umetnosti, 10, 1974, pp. 325-331. M. S. CALÒ MARIANI, Scultura pugliese del XII secolo. Protomagistri tranesi nei cantieri di Barletta, Trani, Bari e Ragusa, in Studi di storia dell'arte in memoria di Mario Rotili. Napoli 1984, pp. 177-191. P. BELLI D'ELIA, I rapporti con l'area dalmata, in R. CASSANO, R. LORUSSO ROMITO, M. MILELLA, Andar per mare: Puglia e Mediterraneo tra mito e storia, catalogo della Mostra (Bari, 1997), Bari 1998, pp. 341-348. M. S. CALÒ MARIANI, La Puglia e l'Europa nel XII secolo, in A. C. QUINTAVALLE (dir.), Medioevo: arte lombarda, atti del Convegno Internazionale di studi (Parma, $26-29$ settembre 2001), Milano 2004, pp. 574- 592. 


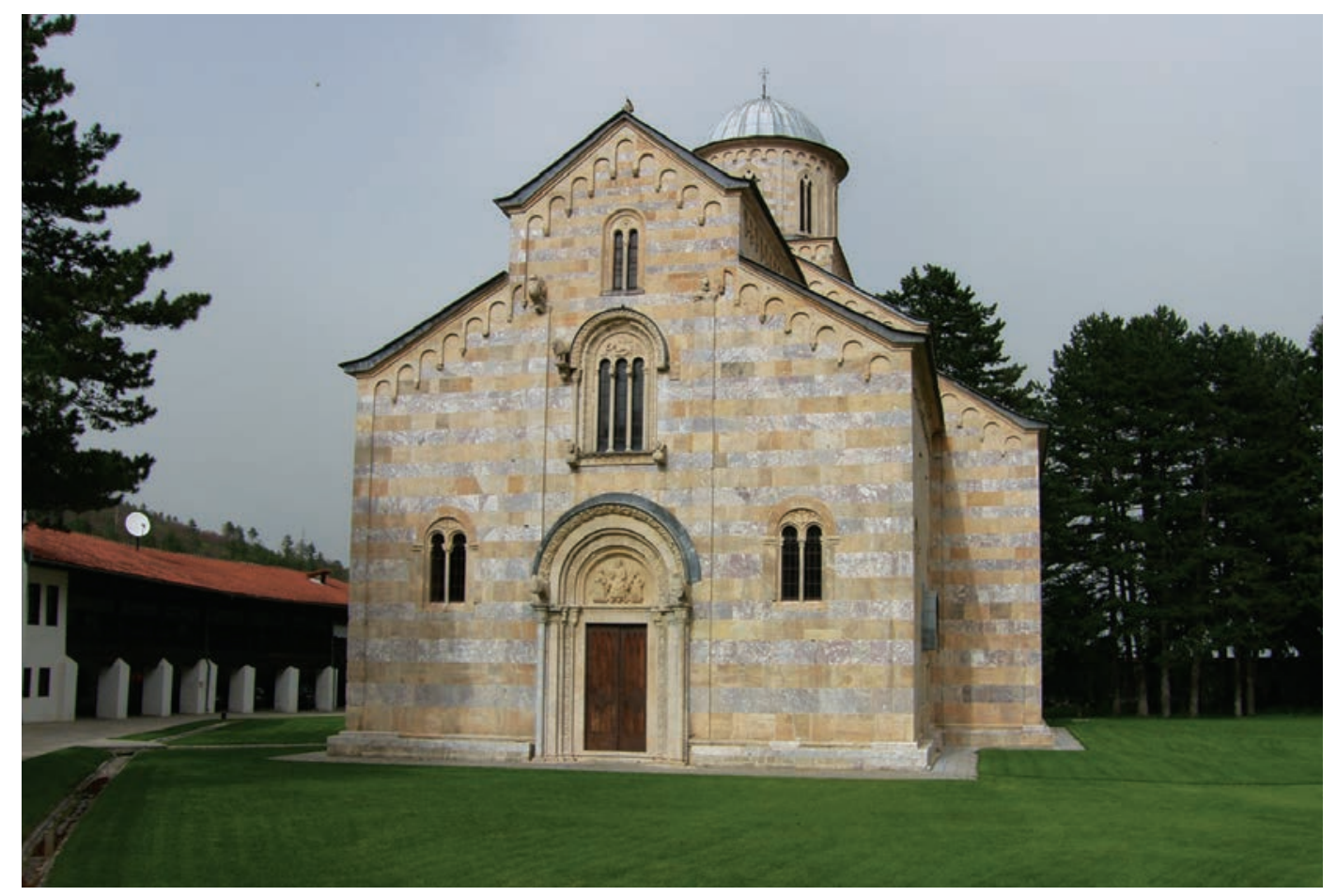

Fig. 14. Dečani, monastero del Cristo Pantocratore, il katholikon.
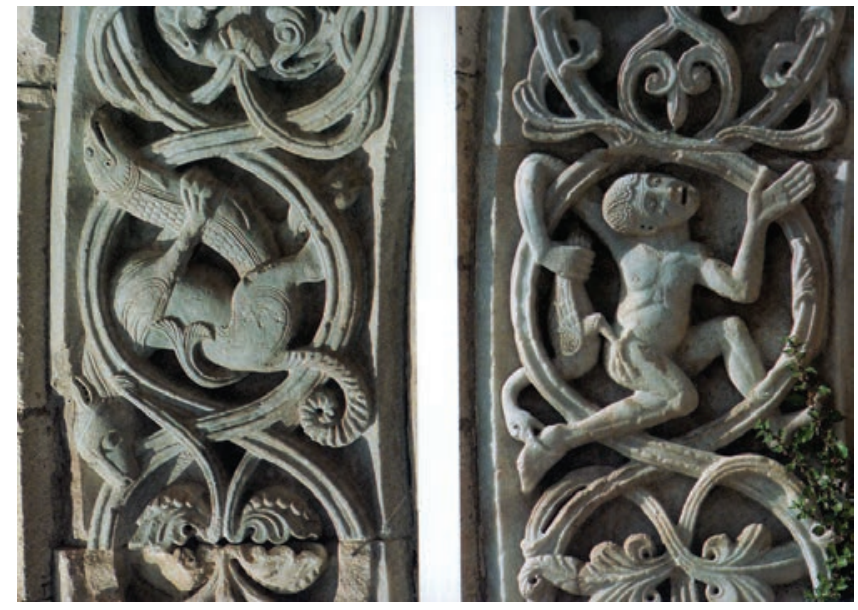

Fig. 12. a-b. Trani, cattedrale di S. Nicola Pellegrino, dettagli del portale maggiore (da P. Belli d'Elia, 2003).

che nomina un protomagister Eustasius, figlio di Bernardo $\mathrm{d}^{\prime}$ Apulia ${ }^{68}$. La mano del maestro è stata riconosciuta anche in alcuni frammenti lapidei custoditi nel locale museo che mettono in mostra le rispondenze iconografichee le modalità d'intaglio della pietra già denotate nel portale tranese ${ }^{69}$.

Contemporaneamente, l'alta lezione dei due scalpellini, caratterizzata da una qualità eburnea del rilievo, tanto da lasciar sospettare alla Calò Mariani una carriera anche nell'intaglio dell'avorio, si diffuse nei cantieri di Terra di Bari come oltremare, con la dispersione delle maestranze ed il transfer, anche da generazione a generazione, di modelli e modi plastici di successo, eleganti e qualificanti, replicati ancora per tutto il secolo successivo. In una società che scopriamo sempre più mobile rispetto ai topoi, essi avevano il compito di risvegliare suggestioni, confronti e parallelismi

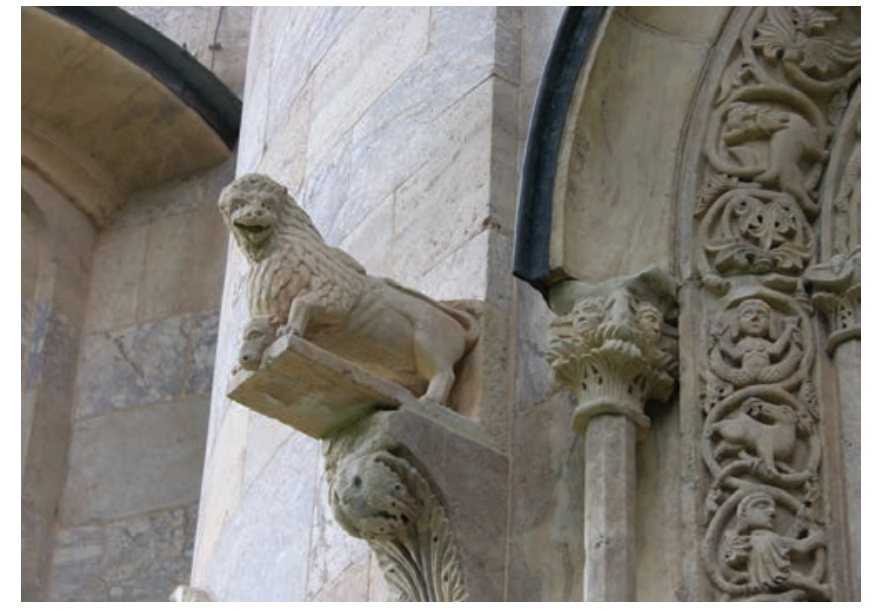

Fig. 13. Dečani, monastero del Cristo Pantocratore, dettagli della finestra absidale del katholikon.

presso i devoti: pellegrini, commercianti, diplomatici, aristocratici o clerici, oppure individui mossi dal mero desiderio di conoscenza e di aggiornamento come i creativi, gli artisti o meglio gli artefici, e gli uomini di cultura in generale. In quei decenni era aperto anche il cantiere della chiesa della Vergine di Studenica, prima chiesa con valore dinastico per i Nemanjić. Per quello che è noto possiamo ipotizzare che talune maestranze furono reclutate dal litorale o addirittura dall'Italia meridionale ${ }^{70} \mathrm{e}$ vi misero in opera un repertorio, tanto architettonico che negli ornati, di ascendenza occidentale che si pone in continuità, come l'anello di una preziosa catena, trasmettendo tecniche, modi plastici e iconografie (figg. 10 - 11; $12 \mathrm{a}, \mathrm{b}$ - 13) fino alla più nota e tarda chiesa del Pantocratore di Dečani (1327 - 1335), opera del protomagister Vita, francescano proveniente da Cattaro ${ }^{71}$. A quell'epoca

\footnotetext{
${ }^{68}$ Ved. supra n. 67.

${ }^{69}$ In partic. M. S. CALÒ MARIANI, La Puglia e l'Europa... op. cit., (n. 67).

${ }^{70}$ V. KORAĆ, L'architecture du monde serbe, in C. D. FONSECA (dir.), Le aree omogenee della Civiltà Rupestre nell'ambito dell'Impero Bizantino: la Serbia, atti del quarto Convegno Internazionale di studio sulla Civiltà Rupestre medioevale nel Mezzogiorno d'Italia (Taranto-Fasano, 19-23 settembre 1977), Galatina 1979, pp. 117-137. S. ĆIRKOVIĆ, op. cit. (n. 29). S. ĆURČ́Ć, op. cit. (n. 35), pp. 496-498.

${ }^{71}$ G. SUBOTIĆ, Terre Sacrée du Kosovo, Paris 2006, pp. 177-197. S. ĆURČIĆ, op. cit. (n. 35), pp. 659-661.
} 


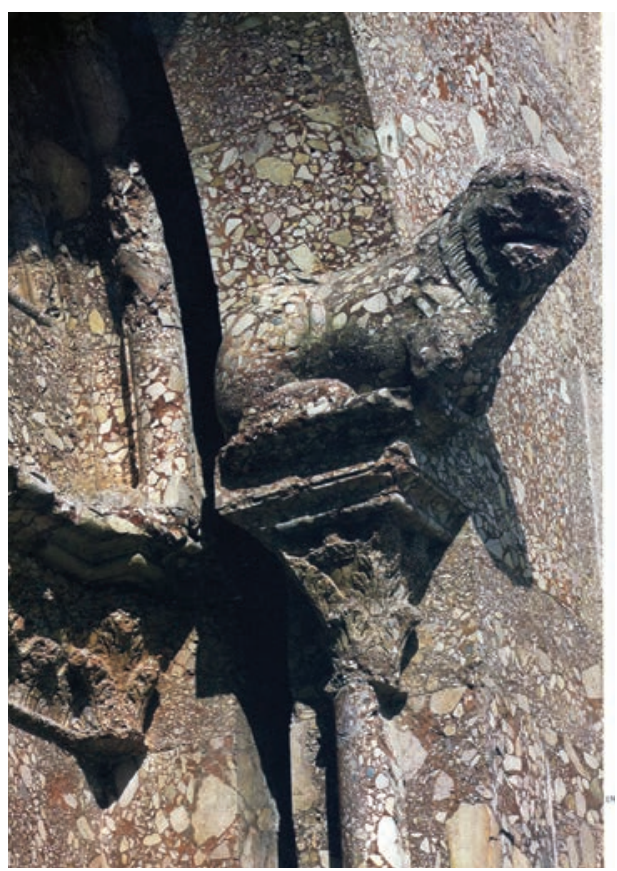

Fig. 15. Andria, Castel del Monte, dettaglio del portale d’ingresso (da M.S. Calò Mariani, 1984).

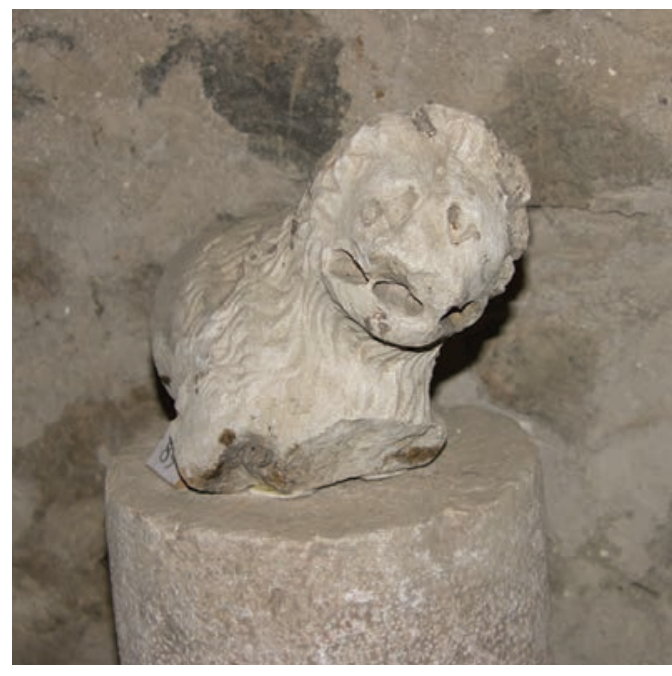

Fig. 16. Scutari, Museo Storico, leone acroteriale.

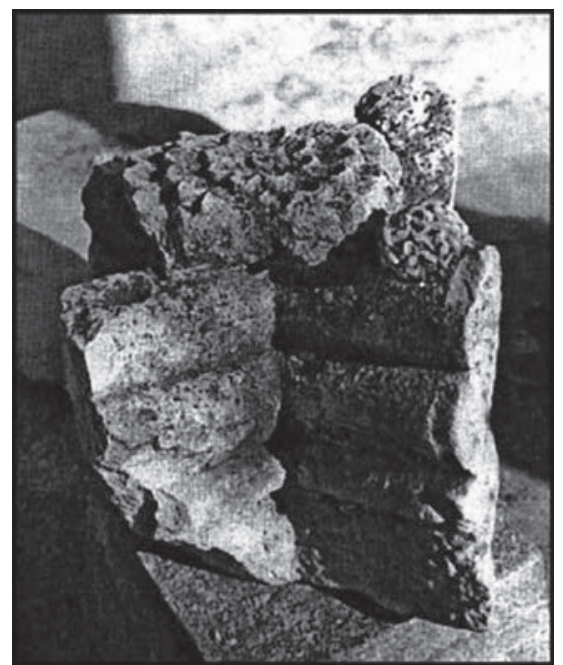

Fig. 17. Durazzo, Museo Archeologico, chiave di volta erratica (da A. Meksi, 2004). ormai i campionari delle soluzioni decorative come di quelle strutturali erano sedimentati e cristallizzati anche a tali latitudini, diventati lemmi di un lessico ibrido che potremmo definire "Romanico di Serbia” (fig. 14), anche se introduce e fa convivere elementi della tradizione gotica del XIII e XIV secolo. Il risultato determina uno stile flessibile e declinabile ad uso e consumo di committenti e comunità, cattoliche o ortodosse, che con la stessa flessibilità adatta architettura e linguaggi decorativi alla diversa spazialità dei contenitori religiosi, siano essi per il rito latino o greco. Proposte culturali vincenti che oltrepassano facilmente sia i confini geografici, sia quelli fra diverse società, diventando quasi universali ed emblematiche, dialetto locale di una koinè mediterranea.

Dalle chiese di Trani a quelle di Barletta, Bari e Monopo$\mathrm{li}^{72}$, fino al litorale balcanico e alla Rasha è un fiorire di tralci popolati lungo gli archivolti di portali e finestre. Carnosi e ritmicamente sinuosi avviluppano agili soldati, figure di nudi, esseri mitologici e mostruosi ma anche animali reali che vi si arrampicano o accompagnano l'intreccio vegetale animandone i vuoti come dentro formelle. Temi ripresi da maestranze emule che tramandano nel tempo e nello spazio anche quei modi plastici "eburnei" nei finestroni absidali tanto di Studenica che di Dečani, i quali proseguono il trend inaugurato nella cattedrale tranese e perfezionato lungo le traiettorie pugliesi e dalmate.

Contemporaneamente l'Albania era una compagine culturale in divenire, similmente divisa fra territori e comunità di diverso orientamento politico-religioso. Anch'essa, purtroppo solo per frammenti, dimostra di essere informata ed inserita in questa circolazione transadriatica, capace di selezionare un repertorio proveniente da quelle traiettorie e di riapplicarlo in più e diversi contesti. Aggiornata sugli sviluppi intrapresi dalla cultura artistica del Mezzogiorno d'Italia e avendo l'esclusiva nei Balcani per quanto riguarda l'adozione del modulo degli archi intrecciati a ingentilire gli esterni di importanti fondazioni.
In questa catena spazio-temporale, Belamarić distingue con chiarezza un momento di passaggio fra il romanico ed i primi impulsi gotici73, ravvisabile in alcuni cantieri della fascia costiera dalmata, ancora una volta sintonizzata verso i fenomeni provenienti dall'oltremare. Differisce l'entroterra serbo dove, più che un graduale innesto, si avverte il gusto per l'ibridazione e la mescola di elementi alloctoni. Nel secondo Duecento e ai primi del secolo successivo, lo studioso riconosce una serie di cantieri che mediano il passaggio fra le due culture architettoniche, come avviene nell'atrio della cattedrale di Traù dove furono attivi lapicidi che, nei capitelli e nelle volte costolonate, impiegarono un repertorio prossimo a quello di Castel del Monte. Altri esempi ancora, veicolarono spunti protogotici a fine XIII secolo e ai primi del Trecento, come il portale della chiesa francescana di Pola o quello della cattedrale di Zara, scendendo fino a Dubrovnik con la chiesa dei Domenicani ${ }^{74}$.

Di questo "stile di transizione" è possibile riconoscerne alcune tracce anche in area albanese, molte già individuate da Meksi, ma ulteriori testimonianze, purtroppo sempre frammentarie e spesso fuori contesto, sono sparse lungo l'Albania e dimostrano come, in continuità col litorale dalmatico, i prodotti artistici erano strettamente legati al panorama d'oltremare (figg. 15-16-17).

Questo momento può fare da sfondo alle vicende costruttive della già menzionata chiesa abbaziale dei Ss. Sergio e Bacco del villaggio di Shirgj, sul versante albanese della Buna, della quale più nulla resta se non pochi ruderi a causa delle piene di quel fiume e della lussureggiante vegetazione che ne hanno minato la stabilità durante secoli di abbandono. Il sito era crocevia della rete di comunicazioni terrestri e fluviali fra la costa e Scutari, sin dall'istituzione della provincia tardoantica della Praevalitana.

La posizione felice ed il favore dei regnanti, quindi l'inclusione nei commerci veneziani, furono alla base della prosperità acquisita dall'abbazia e dallo scalo fluviale negli ultimi secoli del medioevo. Sulle banchine di portus sancti Sergii de Drino ${ }^{75}$, (così chiamato perché nella Buna confluisce anche un ramo del più ampio e noto fiume) si commerciavano i prodotti dell'entroterra e il sale, la città era sede

\footnotetext{
$\overline{7^{2}}$ M.S. CALÒ MARIANI, Scultura pugliese del XII secolo... op. cit. (n. 67); EAD. La Puglia e l'Europa nel XII secolo... op. cit. (n. 67).

${ }^{73}$ J. BELAMARIĆ, Studije iz starije umjetnosti na Jadranu, Split 2012, vol. 2, pp. 575-576.

${ }^{74}$ Ibidem.

75 K. JIREČEK, Skutari und sein Gebiet im Mittelalter, in Illyrisch-albanische Forchungen, 1936, p. 106.
} 


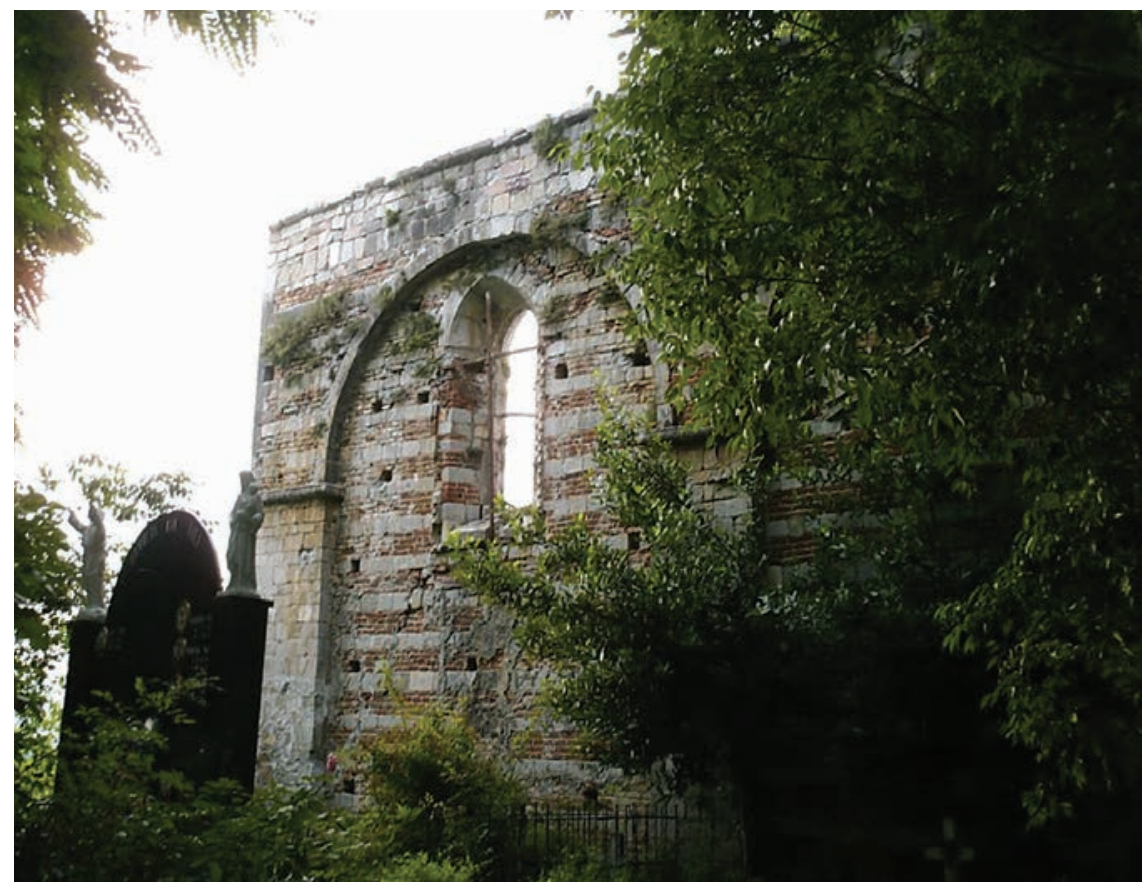

Fig. 18. Shirgj, rovine dell'abbaziale dei Ss. Sergio e Bacco (stato di conservazione 2009).

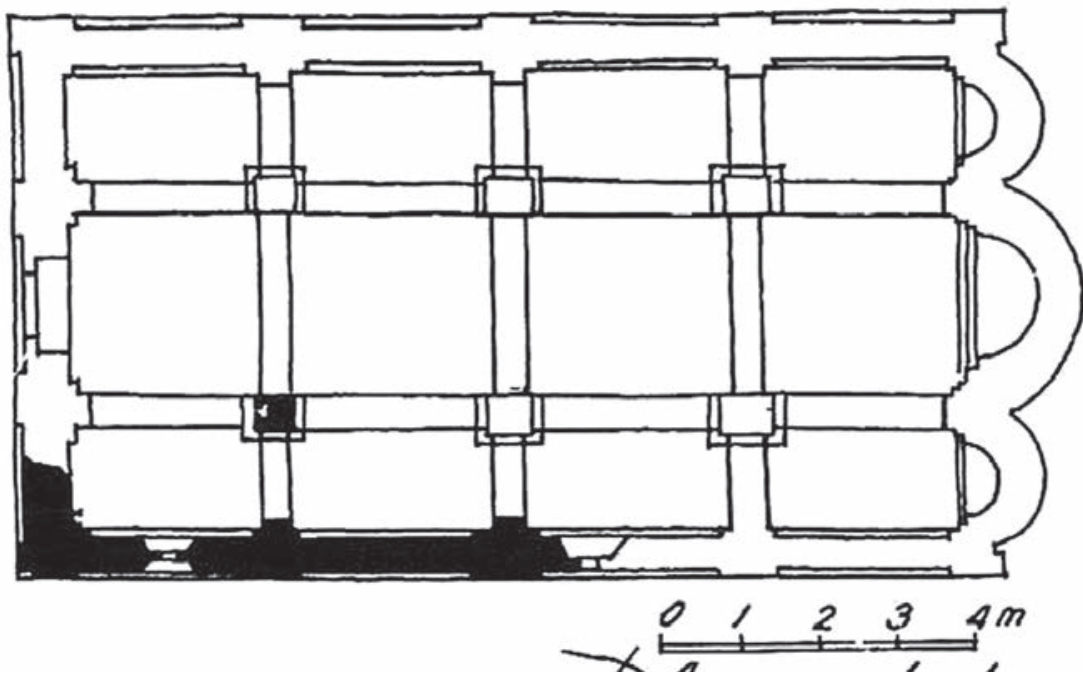

Fig. 19. Shirgj, planimetria dell'abbaziale dei Ss. Sergio e Bacco (da A. Meksi, 2004). anche quella militare: nel 1335 è registrato un castellanis sancti Sergii ${ }^{77}$; nel secolo successivo, con il passaggio alla Serenissima Repubblica, documenti veneziani del 1422, 1423 e 1474 ricordano la flotta lì ormeggiata a difesa del lago di Scutari e dell'omonima città ${ }^{7}$.

Una preesistente basilica giustinianea ${ }^{79}$ spiegherebbe la devozione ai martiri siriani, fondata in un momento di espansione del culto verso occidente nel VI secolo ${ }^{80}$, culto che ha lasciato altre testimonianze lungo quella costa con chiese dedicate e reliquie ${ }^{81}$. Da quel primo edificio fu rielaborata la tecnica d'esecuzione impiegata nella seconda ricostruzione della chiesa abbaziale, eretta alternando quattro filari di mattoni e un corso di conci lapidei, con le parti portanti, archi, semipilastri e pilastri, unicamente in pietra (fig. 18). Il primo insediamento benedettino sembra essere sorto nell'XI secolo nei pressi della basilica bizantina ${ }^{82}$. Dovette assurgere velocemente a grande importanza lungo quel litorale ed il suo abate, Petro, detto anche archimandrita nel solito documento del 1166, presenziò alla consacrazione degli altari del S. Trifone di Cattaro. Notizie certe riguardano una ricostruzione intrapresa nell'ultimo decennio del XIII secolo e documentata da ben due epigrafi dedicatorie. La prima farebbe riferimento all'inizio dei lavori nel 1290, da attribuire alla regina Elena, moglie francese e cattolica di Stefano Uroš Nemanjić. A lei si deve un'intensa attività di promozione e protezione degli ordini religiosi romani in tutto il regno. Il testo è scolpito su una lastra conservata nel Museo Nazionale di Tirana e così dice ${ }^{83}$ :

MEMENTO DOMINE FAMULE TUE HELENE REGINE SERVIE DYOCLIE ALBANIE CHILMIE / DALMACIE ET MARITIME REGIONIS QUE / UNA CUM FILIIS SUIS REGIBUS UROSIO ET STEPHANO EDIFICAVIT DE NOVO ISTAM ECCLESIAM / AD HONOREM BEATORUM MARTIRUM della dogana e vi si teneva una fiera a fine settembre ${ }^{76}$. Alla topografia commerciale e religiosa, che comprendeva altre tappe fra Scutari e la costa di Dulcigno, si sovrapponeva
SERGII ET /

BACHI ET AD FINE (SIC) USQUE /

CO[M]PLEVIT ANNO DOMNI M.CC.LXXXX.

\footnotetext{
${ }_{7^{6}}$ A. BAÇE, A. ALEKSI, Skelat grykëlumore të Adriatikut gjatë mesjetës shek. XI-XV (riass. Les quais des embouchures de l'Adriatique au cours du Moyen Age), in Monumentet 1, 1986, pp. 25-34.

77 Č. MIJATOVIĆ, Despot Djuradj Branković, gospodar Srbima, Podunavlju i zetskom Primorju, Belgrad 1907, vol. I, p. 40.

${ }^{8}$ Ibidem; K. JIREČEK, op. cit., (n. 75); A. BAÇE, A. ALEKSI, op. cit. (n. 76).

${ }^{79}$ J. NERALIĆ, Opatija sv. Sergija i Baka i njeni opati tijekom 15. stoljeća prema dokumentima Tajnoga vatikanskog arhiva, in Poeta nascitur, historicus fit: ad honorem Zef Mirdita, Sangallo - Zagabria 2013, pp. 141 - 167.

${ }^{80}$ P. XHUFI, op. cit. (n. 9).

${ }^{81}$ Una chiesa di culto greco dedicata ai due martiri è presente a Himara, a sud di Valona, datata fra X-XI secolo, cfr. A. MEKSI, op. cit. (n. 24), pp. 143-144. La venerazione in generale sembra essere ben rappresentata su entrambe le sponde dell'Adriatico da varie altre testimonianze cultuali come a Cattaro dove D. FARLATI (Illyricum Sacrum, Venezia 180o, vol. 6, p. 428) certifica l'esistenza di reliquie custodite nella chiesa di S. Paolo. Ė nota poi la presenza di chiese dedicate in quell'area, oltre che a Cattaro anche a Ragusa, dove sembrerebbe uno dei culti più antichi, così come a Trani in Puglia. Sulla diffusione del culto in area adriatica si guardi la recente e sistematica indagine di D. PRERADOVIĆ, Bisanzio sull'Adriatico nel IX eX secolo. Topografia sacra. (Tesi di dottorato XXII Ciclo), Università degli Studi di Udine - École Pratique des Hautes Études, a.a. 2010-2011. Ringrazio la studiosa per avermi generosamente concesso l'accesso al suo lavoro. Mentre in area veneta una reliquia con reliquiario in forma di braccio è conservata nella cattedrale di S. Maria Assunta di Chioggia la cui provenienza è, ancora una volta, da ricercarsi a Cattaro. N. JAKŠIĆ, Un gruppo di reliquiari trecentesci da Cattaro a Venezia e Chioggia, in G. BALDASSARI, N. JAKŠIĆ, Ž. NIŽIĆ (dir.), Letteratura, arte, cultura tra le due sponde dell'Adriatico, Zadar 2008, pp. $219-237$.

${ }^{82}$ J. NERALIĆ, op. cit. (n. 79).

${ }^{8}$ Ibidem.
} 
La seconda iscrizione invece è frammentaria e abrasa in più parti, incisa sull'architrave del portale maggiore conservato presso il Museo Storico di Scutari; da essa emergono altri riferimenti ai sovrani serbi e cita, ancora una volta, un abate di nome Petro. La data, parzialmente perduta, è stata interpretata dagli studiosi come $1318^{84}$. L'icnografia basilicale della fondazione nemanjide è tramandata da immagini storiche e da indagini in loco sulle rovine compiute nei decenni addietro dall'arch. Aleksandër Meksi, redattore della planimetria (fig. 19). Essa corrisponde ad un impianto benedettino, congruente con un edificio dell'XI secolo di cui si mantennero le caratteristiche ancora nel XIV secolo. Si trattava di una chiesa a tre navate, priva di transetto e conclusa da absidi estradossate. La nave maggiore era scandita da pilastri, collegati da archi alle corrispondenti paraste che ritmavano i muri perimetrali e contemporaneamente sorreggendo archi ciechi in spessore di muratura. Questo sistema strutturale, replicato anche lungo gli esterni ed in facciata, era compatibile con una copertura a volte per le navatelle. Per contro, sulla navata centrale le due file divisorie di esili pilastri a base rettangolare dovevano sostenere una copertura leggera come un tetto ligneo. L'uso del pilastro, applicato anche nella nota abbaziale di S. Pietro d'Ossero dell'XI secolo, risulta più frequente nelle fondazioni d'ambito cassinese della fascia medio-adriatica italiana, particolarmente in area abruzzese, quali S. Liberatore alla Majella presso Pescara e S. Pietro Campovalano presso Teramo, le cui fasi di fondazione o rifondazione s'inscrivono anch'esse nell'XI secolo ${ }^{85}$.

Nella chiesa albanese, la sequenza continua degli arconi ciechi lungo le fiancate rimandava a schemi diffusi nel Mezzogiorno italiano; ogni arcata inquadrava una monofora lievemente archiacuta, sguanciata e incorniciata con motivi decorativi dal delicato intaglio, mentre la facciata era scavata da ogive in spessore di muratura. Queste caratteristiche filtrano gli elementi di un primo gotico sobrio che tenta di aprirsi una via balcanica, adeguandosi ad edifici che rispondono a soluzioni strutturali e tipologie planimetriche ancora pienamente romaniche.

Nel novero di questo fenomeno, va menzionata anche la chiesetta di S. Maria di Vau i Dejës, località raggiungibile risalendo il corso del Drin. Cancellata con la dinamite delle milizie del regime comunista albanese nel 1967, non solo per compiacere la brutale imposizione laicista del governo, ma probabilmente anche perché percepita come un elemento culturalmente estraneo. Di essa rimangono solo le fondamenta tracciate nel suolo e alcune foto storiche che ne documentano l'aspetto di piccolo sacello (fig. 20), poi incluso in un più ampio complesso di gusto neoromanico. L'antico edificio, se da un lato mostrava strette analogie con l'abbaziale dei Ss. Sergio e Bacco nella scansione esterna delle fiancate per arcate cieche, qui acute; dall'altra rifletteva taluni aspetti dell'architettura serba che sembrano riadattarsi e ritornare in un contesto latino. Tale risultato potrebbe dipendere da ampie ricostruzioni in stile, ma è ben adattato al contesto storico in cui la chiesa fu edificata.

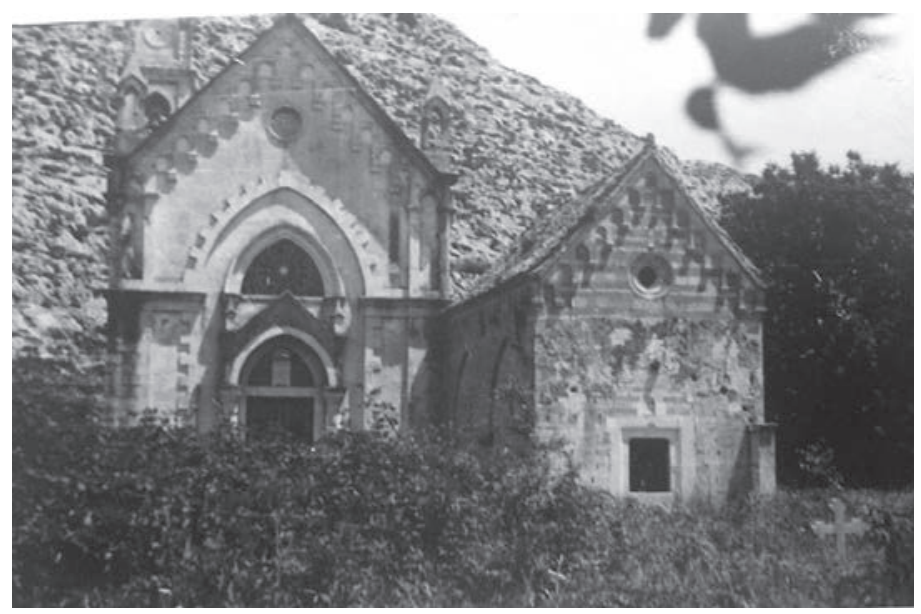

Fig. 20. Vau i Dejes, chiesa di S. Maria prima della demolizione (da www. radiandradi.com).

Essa cita chiaramente i caratteri compositivi e formali più diffusi fra il litorale diocleano e i cantieri reali della Rasha, in una versione ridotta. La piccola costruzione, un'aula unica composta da due campate, ad uso di una modesta comunità cattolica, condivideva con i cantieri reali l'uso della bicromia e il coronamento ad archetti ciechi "alla lombarda".

Il primo documento che cita l'edificio fu promulgato da Stefano Dušan presso la chiesa dei Ss. Apostoli di Prizren nel 1348. Sebbene potrebbe trattarsi di un largo terminus ante quem, allo stesso tempo non è possibile non considerare come sia solo un decennio dalla chiusura del cantiere di Dečani. Pochi anni prima poi, Dušan aveva esteso il suo potere anche sull'Albania e su tutti i Balcani meridionali a seguito delle sue conquiste per cui si era proclamato "zar dei Serbi, dei Greci, dei Bulgari e degli Albanesi” nell'aprile del $1346^{86}$. La chiesa di Vau i Dejës testimoniava la diffusione di modelli associati al potere, a carattere simbolico o celebrativo dei suoi fondatori, ma allo stesso tempo legata a problematiche più concrete, quali la circolazione di maestranze e modelli ancora una volta veicolati dall'Itinerarium Lissus-Naissus e dagli assi fluviali attrezzati con scali commerciali.

\section{3) LA CORRENTE MERIDIONALE: FRA ARBANON ED EPIRO.}

Più a sud, al confine tra Arbanon ed Epiro albanese, idealmente tratteggiato da un diverticulum meridionale della Via Egnazia, ad alcuni chilometri dalla costa e presso le rovine dell'antica città di Apollonia, prima stazione di quell'itinerario, fra XI e XIII secolo sorse un monastero ortodosso dedicato alla Theotokos. La città risaliva al VII secolo a.C., fondata come colonia corinzia divenne una delle più note e ricche in età romana lungo quell'asse. Decadde fra tardo antico e primo medioevo, rimanendo un sito di austere rovine per secoli, quinta scenica per una fondazione religiosa che si poteva provvedere facilmente di materiali e spolia di grande qualità. La chiesa con il suo nartece è la prova di come la fascinazione per l'arte monumentale d'Occidente non fu un'esclusiva del regno serbo, e

\footnotetext{
${ }^{84}$ A. MEKSI, Kishat mesjetare tëShqipërisë së mesme të veriut (riass. Les églises moyenageuses de l'Albanie centrale et de l'Albanie du nord), in "Monumentet", 2, 1983, pp. 77-117. ID., op. cit. (n. 24), pp. 202-205. W. KAMSI, Kisha e kuvende të Shkodrës me rrethina në Mesjetë (riass. Churches and convents in Shkodra and its surrounding area in the middle ages), in Krishtërimi ndër Shqiptarë, Simpozium Ndërkombëtar, Tiranë, 16-19 Nëntor 1999, Shkodër 200o, pp. 119-130. ${ }^{85}$ G. CARBONARA, Montecassino e l'architettura campano-abruzzese nell'undicesimo secolo, Roma 1970, pp. 147-187. M. MORETTI, Architettura medievale in Abruzzo (dal VI al XVI secolo), Roma s.d., pp. 14-30, 54-59.

${ }^{86}$ A. DUCELLIER, op. cit., (n. 5), pp. 357-359. ĆIRKOVIĆ S., op. cit. (n. 29), pp. 136, 155.
} 


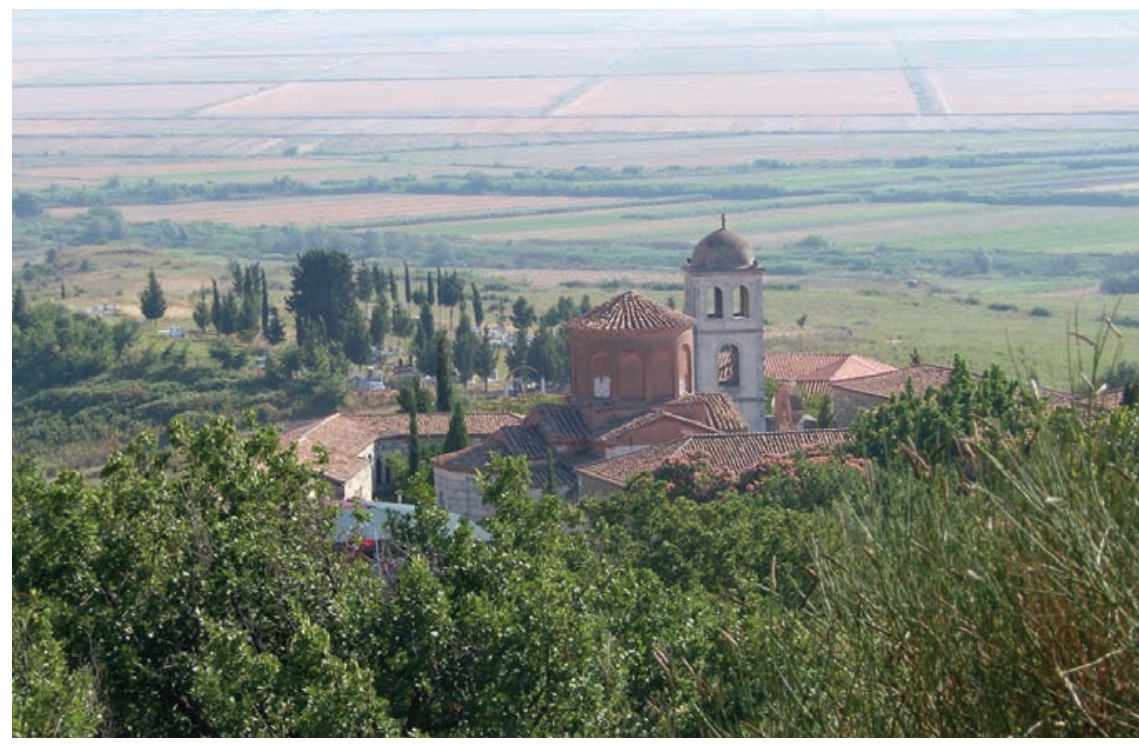

Fig. 21. Apollonia, monastero della Theotokos.

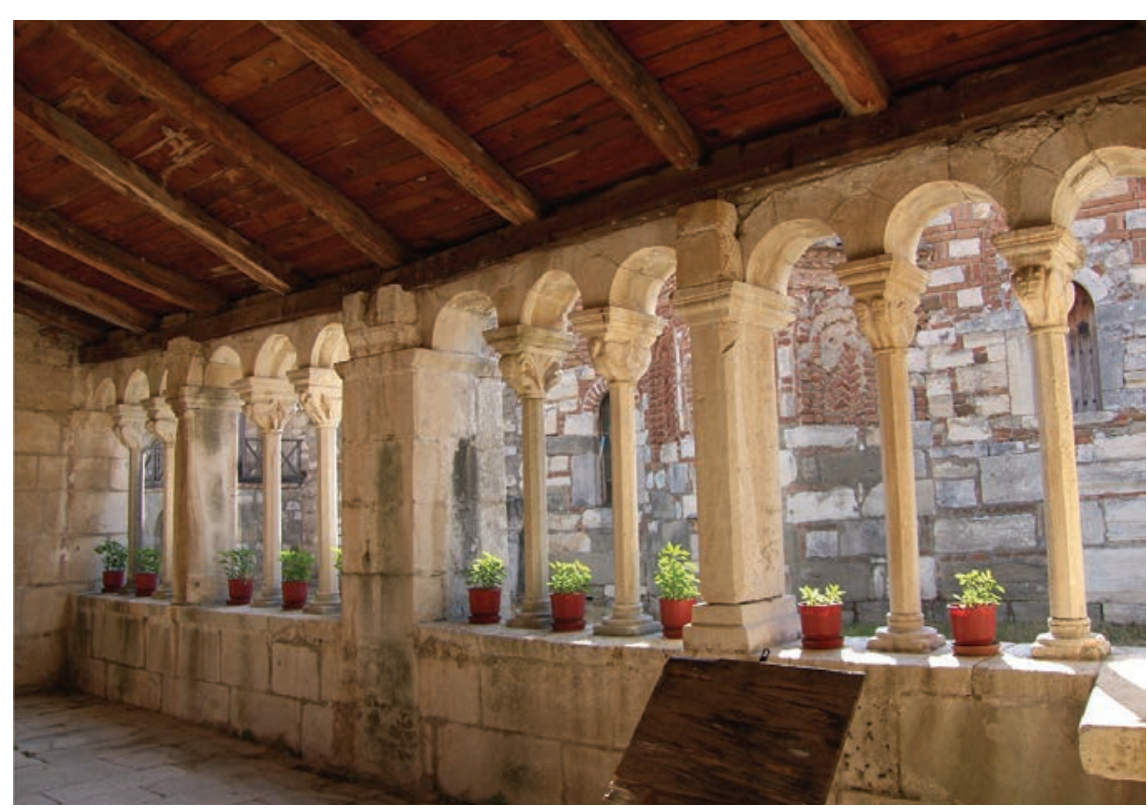

Fig. 22. Apollonia, monastero della Theotokos, nartece del katholikon.

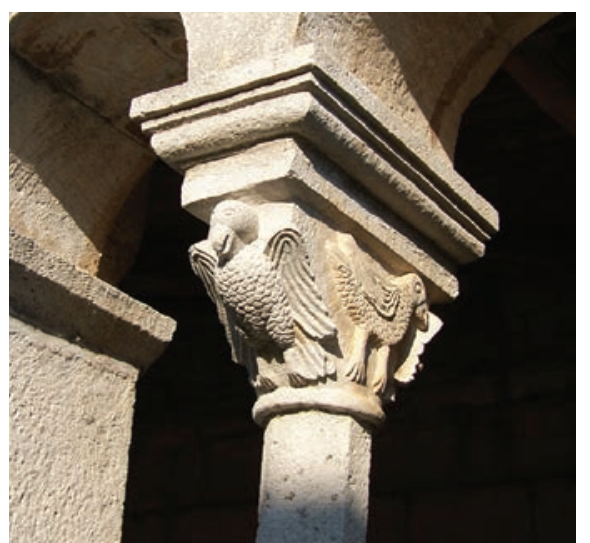
dettaglio di un capitello del nartece.
Fig. 23. Apollonia, monastero della Theotokos,

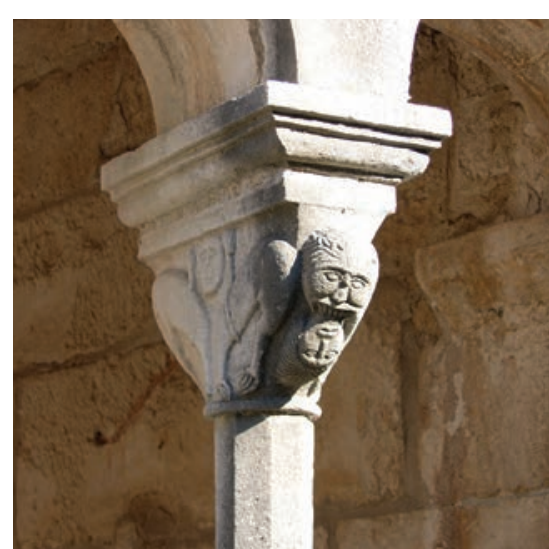

Fig. 24. Apollonia, monastero della Theotokos, dettaglio di un capitello del nartece. come alcuni monasteri o chiese greco-ortodosse riuscirono parzialmente a incorporarlo, mitigandolo o piegandolo alle loro esigenze. La delineata mobilità di modelli e maestranze sulle rotte per l'Oriente interessò anche le coste meridionali dei Balcani, aprendosi una strada diretta all'Epiro che, transitando per Apollonia, metteva in comunicazione l'intera costa da nord a sud. L'insediamento fu così eretto in uno spazio di frontiera, circondato dalle rovine dell'antica città greco-romana le quali contribuivano a enfatizzarne l'aura sacrale. Posto in posizione elevata, sui primi dolci declivi che dominano la fascia costiera albanese meridionale, ancora oggi quel complesso gode di una localizzazione eccezionale (fig. 21).

La storiografia tende a includerne la fondazione in un arco temporale compreso fra l'impero di Alessio Comneno (1081-1118), ed una fase attribuibile a Michele VIII Paleologo $(† \mathbf{1 2 8 2})^{87}$ testimoniata da un affresco pro anima nell'esonartece. Vi è raffigurata l'intera famiglia imperiale e l'igumeno al cospetto della Vergine a cui viene offerta la maquette dell'edificio. È certamente all'interno di questi due secoli che le vicende costruttive della chiesa si esauriscono e ne vanno ricercati i confronti.

Il katholikon del monastero, pur aderendo alla classica configurazione d'età medio-bizantina, croce greca inscritta in pianta quadrata, nonostante la peculiarità del grande invaso cupolato, costituisce un interessante caso di espianto e riuso di forme e temi estratti dall'arte romanica e applicati all'esonartece, unico nell'ecumene bizantino. Le sue forme e l'apparato scultoreo traspongono oltreadriatico l'architettura di una galleria claustrale, composta da una successione di quattro trifore intervallate da pilastri (fig. 22). Gli archi a tutto sesto delle trifore si appoggiano internamente su due colonnette la cui morfologia ottagonale con i capitelli a stampella, più il repertorio figurato, indirizzano ancora una volta verso la Puglia; mentre il massiccio pilastro centrale termina all'esterno con un capitello appoggiato e libero, posto di fianco, come se fosse un elemento di risulta da non disperdere. Nei capitelli il ricorso al bestiario medievale o al tema degli animali feroci che si scagliano famelici sugli uomini mettono in scena un repertorio estrapolato dalla scultura dell'Occidente latino (figg. 22-23-24). Ma il vero marchio di fabbrica è nell'intaglio volumetrico delle forme, costrette nella geometria del supporto, ingentilite da un grafismo seriale che plasma i dettagli in senso chiaroscurale. Questa plastica, apparentemente

di come in Albania quel lessico non rimase confinato presso le sole comunità cattoliche. Anche realtà più conservative arcaizzante, rimanda alla scultura claustrale dei monasteri dell'area medio pugliese, come quelli dedicati a S. Bene-

\footnotetext{
${ }_{77}^{7}$ H. - H. BUSCHHAUSEN, Die Marienkirche von Apollonia in Albanien. Byzantiner, Normannen und Serben im Kampf um die Via Egnazia, Wien 1976. V. PACE, Mosaici e pittura in Albania (VI-XIV secolo). Stato degli studi e prospettive di ricerca, in Progetto Durrës, l'indagine sui beni culturali albanesi dell'antichità e del medioevo: tradizioni di studio a confronto, atti del I Incontro Scientifico (Parma-Udine, 19-20 aprile 2002), Trieste 2003, pp. 93-127, in partic. pp. 110 e ssg. A. MEKSI, op. cit. (n. 29), pp. 222-230. S. ĆURČIĆ, op. cit. (n. 35), p. 428.
} 


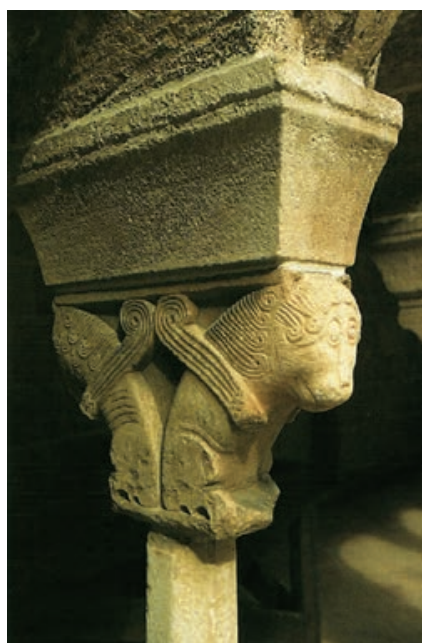

Fig. 25. Brindisi, monastero di S. Benedetto, dettaglio di un capitello del chiostro (da P. Belli d'Elia, 2003).

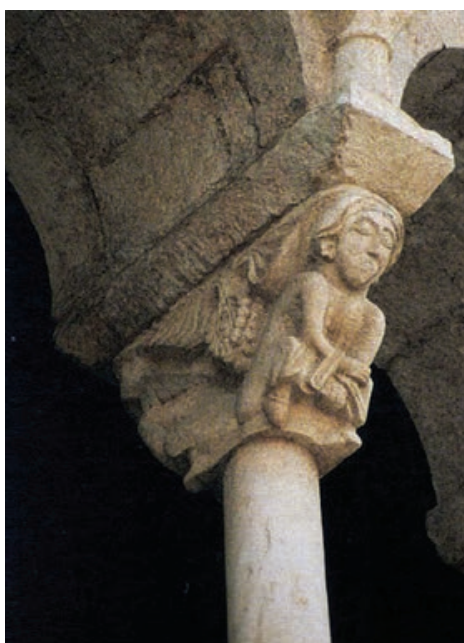

Fig. 26. Bitonto, cattedrale di S. Valentino e S. Maria Assunta, dettaglio di un capitello dell'esaforato (da P. Belli d'Elia, 2003). detto in Bari, Conversano e Brindisi, databili fra XI e XII secolo $^{88}$ (fig. 25); poi travasata negli esaforati delle principali chiese di Terra di Bari dove quello stile ricorre ancora fra XII e XIII secolo (fig. 26). Si riconoscono come elementi caratterizzanti i grandi e vacui occhi a mandorla che quasi privano di espressività anche le scene più atroci, o l'accentuata stilizzazione dei rilievi che fungono da riempitivo sui fianchi dei capitelli. La pittura con la famiglia imperiale paleologa in quel vano invoglia a datare la struttura ad una fase del secondo XIII secolo e contemporanea all'espansione angioina, nel novero degli "attardamenti" balcanici; ma i paragoni pugliesi riportano alla cautela proprio per il loro fluttuare nell'arco di più secoli e, come giustamente ricordato dai Bushhausen, trattasi piuttosto di una cultura visiva e di modi plastici d'età normanna ${ }^{89}$. Non è poi da escludere, anzi è particolarmente consonante con la storia della fabbrica del monastero, che l'intero esonartece possa essere stato realizzato con l'abbondante uso di pezzi di reimpiego e provenienti da un insediamento religioso romano, abbandonato forse a seguito dei burrascosi eventi che, fra tardo XI secolo e ancora nel XIV, trasformarono quel litorale in un'area di scontri. Come visto a Rubik, spesso furono gli insediamenti religiosi al centro delle ritorsioni dell'una o dell'altra fazione. D'altronde è documentata la penetrazione di una comunità monastica almeno fino alla non lontana Durazzo, come ricorda il documento del 1168 citato nelle prime pagine di questo contributo.

In entrambi i casi, l'intero nartece è il prodotto di un flusso costante fra le due sponde meridionali dell'Adriatico, effetto del diffondersi del cattolicesimo e soprattutto di un'estetica e di messaggi legati a quella cultura religiosa, conseguentemente di maestranze formate e richiamate appositamente per metterne in pratica un lessico congruente. Tutto ciò era andato amplificandosi a partire dal tardo XII secolo, causa le continue ingerenze normanne, veneziane, sveve e angioine. Le politiche espansionistiche di queste ultime dinastie sfociarono in unioni matrimoniali con la casa d'Epiro, nel tentativo di legittimare le loro conquiste e di ambire a quel trono. Quella che lambisce Apollonia è la stessa corrente marittima che mette in comunicazione l'Italia meridionale con il sud della Dalmatia e tutta l'Albania, spingendosi oltre lo Stretto d'Otranto ed addentrandosi nel Mar Ionio, infrangendosi sulle coste dell'Epiro greco. Lo stesso fenomeno di selezione, appropriazione e riuso si può osservare all'interno dei confini del Despotato d'Epiro, prodotto politico delle intromissioni occidentali nel Mar di Levante, nato a seguito della Quarta Crociata e della fondazione dell'Impero latino d'Oriente. Nel corso del Duecento domini francesi, o meglio franchi, vi si consolidarono intorno, e ancora dopo la riconquista paleologa di Bisanzio, il Despotato dovette fare i conti con i suoi confini, terrestri e marittimi: il principato di Taranto e il regno di Napoli oltremare; l'isola di Corfù, l'Albania, l'Acaia dei Villehardouins, tutti territori appartenenti agli Angiò o retti da loro feudatari. Le ambizioni della famiglia francese certamente favorirono l'osmosi culturale e di forme artistiche, ed il Despotato fu inserito in tale circolazione a seguito dell'unione avvenuta nel 1294 fra Filippo di Taranto e la principessa Ithmar, erede di quel trono ${ }^{90}$.

La produzione artistica del secondo XIII secolo nei Balcani meridionali certamente si aggancia in maniera diretta o indiretta a questi eventi. Ben noto è il caso della Panaghia Parigoritissa di Arta (fig. 27), massima committenza dei despoti in quegli stessi anni di stretti rapporti, e allo stesso tempo di conflitti, con gli Angiò. L'edificio è la summa di un percorso culturale che tramite le ingerenze occidentali aveva plasmato il gusto dei committenti/fruitori greci. Negli interni, le colonne binate di estrazione romanica e il corredo plastico figurato, già messo in relazione con la scultura pugliese del secolo ${ }^{1}$, più gli archi trilobati gotici, confermano la ricezione di esperienze e di modelli latini. Contemporaneamente sulla sponda pugliese, a Brindisi, città da cui storicamente passavano tutte le attività rivolte al Levante, si lavorava alla chiesa di S. Maria del Casale, ex voto alla Vergine offerto dalla famiglia angioina proprio nel clima delle imprese orientali di quegli anni; ben presto trasformatasi nel manifesto politico-ideologico delle ambizioni del ramo tarantino e della loro consorteria ${ }^{92}$. Vi si trova impiegato l'arco trilobato nel protiro pensile d'ingresso alla luminosa aula unica, fra i primi esempi, a fine XIII secolo, dell'introduzione di quell'elemento architettonico francese nel meridione adriatico. È parte della vivace composizione

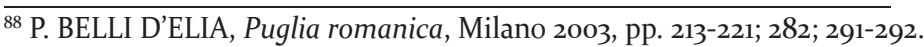

${ }^{89}$ H. - H. BUSCHHAUSEN, op. cit. (n. 87), pp. 17-18.

$9^{\circ}$ É.G. LÉONARD, Gli angioini di Napoli, Varese 1967, pp. 243-246. D.M. NICOL, Thamar, Princess of Taranto 1204-1309, in ID., The byzantine lady: ten portraits 1250-1500, Cambridge 1994, pp. 24-32. T. FRACHERY, L'influence de la Maison d'Anjou en Albanie (1272-1350). Aspects juridiques, religieux et artistiques, in Les Princes d'Anjou. Mémoire et Survivance, in Akademos. Revue de la Conference Nationale des Academies des Sciences, Lettres et Arts, 23, 2005 , pp. 7-26.

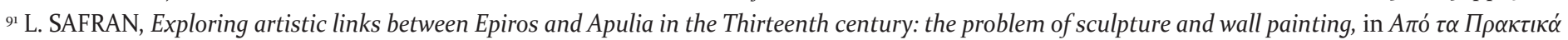

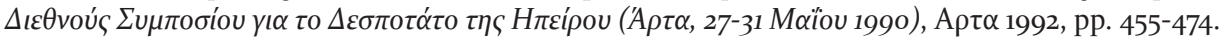

${ }_{92}^{2}$ M. S. CALÒ MARIANI, La chiesa di S. Maria del Casale presso Brindisi, Fasano 1967; EAD., Echi d'Oltremare in Terra d'Otranto. Imprese pittoriche e committenza feudale fra XIII e XIV secolo, in EAD. (dir.), Il cammino di Gerusalemme, atti del II Convegno Internazionale di Studio (Bari-Brindisi-Trani, 18-22 maggio 1999), Bari 2002, pp. 235-274. G. PERRINO, Affari pubblici e devozione privata. Santa Maria del Casale a Brindisi, Bari 2013; G. CURZI, S. Maria del Casale a Brindisi. Arte, politica e culto nel Salento angioino, Roma 2013.
} 


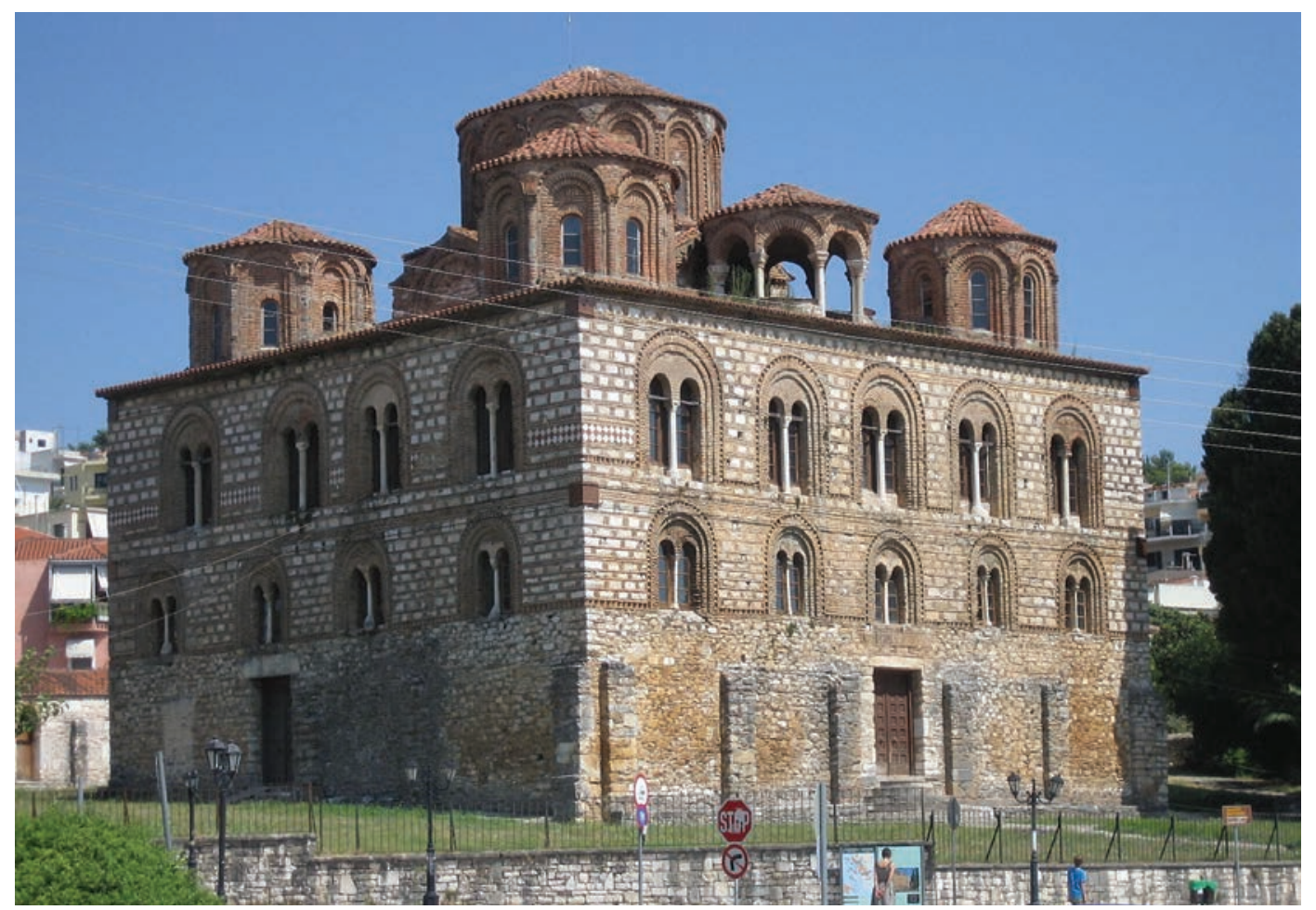

Fig. 27. Arta, chiesa della Panaghia Parigoritissa.

della facciata in cui la fantasiosa bicromia, dovuta all'uso di due differenti materiali lapidei, arricchisce il paramento murario di più fasce contenenti svariati motivi decorativi. Alcune di queste, interamentea losanghe, replicano la medesima decorazione che cinge gli esterni della Parigoritissa fra le bifore del secondo ordine e altri edifici della città di Arta come per esempio anche S. Basilio ${ }^{93}$. Nella Parigoritissa, le finestre disposte parallelamente, insieme al solido aspetto cubico dell'edificio, accentuato da facciate a terminazione rettilinea, hanno determinato il paragone con edifici civici di gusto italiano, avanzato da alcuni studiosi ${ }^{94}$. Osservazione a mio parere valida anche per la facciata orientale e "adriatica" della basilica barese di San Nicola, dove l'assenza delle absidi estradossate, il coronamento rettilineo, il grande finestrone centrale archivoltato a mo' di portale, e la parete forata da bifore, marcano la particolarità dell'edificio (fig. 28), vero e proprio signaculum che identificava la città ed orientava verso il suo principale santuario. Tale operazione concettuale arricchiva di significati e simbolismi quelle forme architettoniche che si muovevano nella mente dei viaggiatori per mare ${ }^{95}$, fossero essi devoti marinai o pellegrini, aristocratici committenti o maestranze specializzate. Ciò interveniva nella scelta di uno schema architettonico rispetto ad un altro, non senza una maggiore o minore rielaborazione della "replica" per meglio declinarla alla cultura ricettrice, al suo gusto estetico, alle diverse tecniche costruttive, oppure alla differente scansione e fruizione degli spazi liturgici per la mise-en-scène di un altro rito.

Sulle rotte adriatico-ioniche del tardo medioevo, i richiami ai punti focali della topografia sacra marittima dovevano essere più frequenti di quelle che sono le tracce a noi pervenute e comprensibili con lo sguardo moderno. Il sistema terrestre delle mansiones e mutationes romane, che nel medioevo si arricchisce con xenodochia e santuari lungo quelle che sono diventate vie di pellegrinaggio, aveva il suo corrispettivo marittimo, fenomeno ancora poco indagato. La chiesa del Casale e la basilica di S. Nicola sono invocate da marinai e pellegrini nella preghiera tardomedievale nota come Sante Parole, quali salvifica visione nei momenti di tempesta o quando, per una ragione o per l'atra, si smarriva la rotta. L'apparire delle rassicuranti e riconoscibili forme architettoniche di una chiesa, ancor più se ben nota, era la concreta manifestazione dell'intervento miracoloso ${ }^{96}$. Un processo intellettuale ed emotivo che certamente contribuì al successo dei culti e concorreva alla scelta e alla trasmissione dei modelli, perché spostava l'attenzione dal santo al santuario. Modelli ben noti anche ai dominatori francesi di questi regni e principati uniti dal mare e dalla navigazione, pellegrini e naviganti loro stessi, fondatori della chiesa del Casale a Brindisi, assidui devoti della basilica palatina barese, in qualche modo connessi con la fabbrica di Arta.

\footnotetext{
${ }_{93}$ Similitudine già notata dal Curzi che colloca difatti S. Maria del Casale in un clima di corrispondenze e relazioni reciproche con un ampio oltremare. Ibidem, pp. 22-23.

${ }_{94}$ C. MANGO, Architettura Bizantina, Venezia 1974, pp. 259-266. A. IACOBINI, Architettura - Area bizantina (1991). Disponibile su: www.treccani.it/enciclopedia/architettura-area-bizantina_(Enciclopedia-dell'-Arte-Medievale)/ .

${ }^{95}$ M. BACCI, L'arte: circolazione di modelli e interazioni culturali. In S. CAROCCI (dir.) Storia d'Europa e del Mediterraneo. Sezione IV. Il Medioevo (secoli $V$-XV). Strutture, preminenze, lessici comuni, vol. 9, Rome 2007, Italy, pp. 581-632.

${ }_{96}^{6}$ M. BACCI, Portolano Sacro. Santuari e immagini sacre lungo le rotte di navigazione del Mediterraneo fra tardo Medioevo e prima Età Moderna, in E. THUNØ, G. WOLF (dir.), The Miracolous Image in the Late Middle Ages and Renaissance. Papers from a conference held at the Accademia di Danimarca in collaboration with the Bibliotheca Hertziana, Rome 31 May - 2 June 2003, Roma 2004, pp. 223-248. M. BACCI, On the Holy Topography of sailors: an introduction. In M. BACCI - M. RHODE (dir.), The Holy Portolano. The sacred geography of navigation. Proceedings of the Fribourg Colloquium 2013, Berlin/ Munich/Boston 2014 (Scrinium Friburgense 36), pp. 7-16.
} 


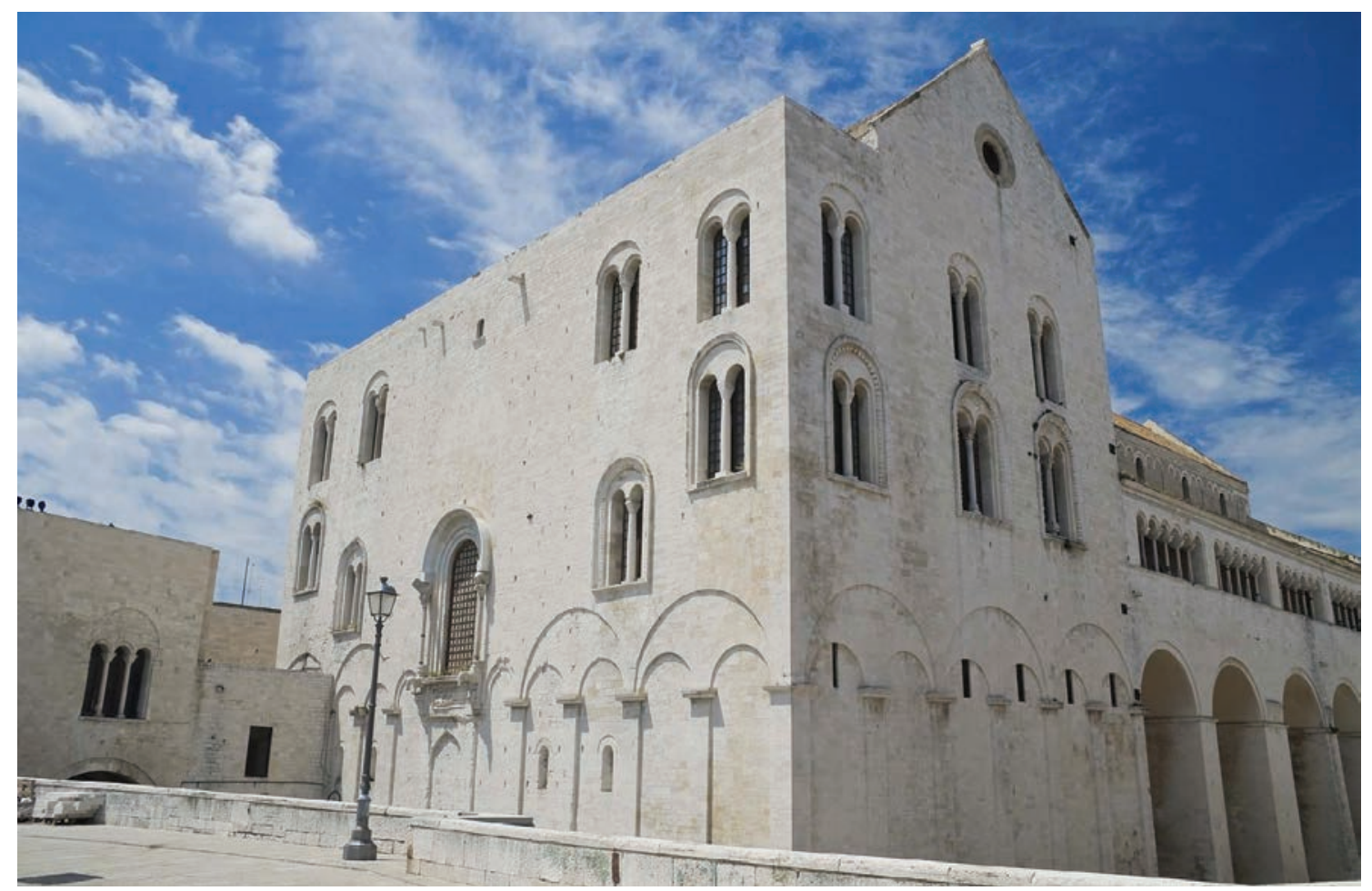

Fig. 28. Bari, basilica di S. Nicola, facciata orientale.

Il tessuto delle rispondenze culturali e dei transfer artistici e concettuali è ancora in divenire per l'Albania. Solo di recente pochi edifici stanno ricevendo una più approfondita attenzione internazionale in un'ottica comparativa degli studi. Fra questi uno dei più noti è certamente il katholikon del monastero fortificato di S. Nicola presso Mesopotam. Localizzato più a sud di Apollonia e nell'immediato entroterra di Saranda, il cui golfo si affaccia sullo Stretto di Butrinto.

Pur presentando varie problematiche relative al cattivo stato di conservazione e alle molteplici stratificazioni e ricostruzioni che ne hanno alterato l'icnografia originaria, gli studiosi che hanno approfondito il caso convengono nell'individuare delle fasi importanti fra XIII eXIV secolo ${ }^{97}$. Queste trovano rispondenza anche dai rinvenimenti ceramici del "tipo Taranto" ed hanno come limite temporale proprio il crinale fra quei due secoli ${ }^{98}$, mettendo in luce un asse di scambi commerciali e culturali che unificava i territori dell'Albania costiera meridionale con la Puglia peninsulare, coprendo il periodo in cui il dominio angioino del ramo tarantino si estese su entrambe le sponde ${ }^{99}$. Potrebbe essere congruente la pavimentazione del nartece che conserva tre flours de lis realizzati a mosaico i quali, seppur non araldici, per Meksi sono il segno dell'ingerenza della Maison d'Anjou in quell'area ${ }^{100}$.

I gigli che invece campeggiano a Rubik, ai piedi della figura affrescata che rappresenta non a caso la Maestà del Cristo, spiegano lì tutta la loro valenza simbolica in accordo con la datazione al fatidico 1272 nella vicina epigrafe, con un programma per immagini teso a celebrare la Chiesa Romana ${ }^{101}$. Quell'emblema sembra essere entrato nel patrimonio della visual culture albanese del XIV secolo con tutti i suoi simbolismi. Applicabile e comprensibile anche nei più tradizionali contesti ortodossi, sotto la spinta di committenti edotti ai suoi significati, inclusi nelle maglie delle ampie alleanze e parentele angioine, volte a consolidare quella stirpe nei territori di loro interesse. Il fleur de lis compare sempre più spesso anche negli emblemi dell'aristocrazia albanese a partire proprio da questo momento. Ritorna, ad un secolo di distanza dagli affreschi di Rubik, nel monastero dedicato al principe di Dioclea S. Giovanni Vladimiro, vissuto fra la fine del X secolo e l'inizio dell'XI ${ }^{102}$. Questa fondazione fu opera di un altro principe, Carlo Thopia, che traslò le sacre spoglie appositamente da Durazzo ad Elbasan nel 1381, dopo che queste erano state già oggetto di un furtum sacrum, dalla città di Dioclea a Durazzo nel secolo precedente ${ }^{103}$.

${ }_{97}$ A. MEKSI, op. cit. (n. 24), pp. 235-240. Così come gli studi ed i risultati delle analisi contenute nei vari saggi in M. BORIANI - G. MACCHIARELLA (dir.), Albania e Adriatico meridionale. Studi per la conservazione del patrimonio culturale, Firenze 2009. G. MACCHIARELLA, Un caso a sé: San Nicola di Mesopotam (Albania), in L. DEROSA - C. GELAO (dir.), Tempi e forme dell'arte. Miscellanea di Studi offerti a Pina Belli d'Elia, Foggia 2011, pp. 123-136.

${ }_{98}^{8}$ S. XHYHERI, Nuovi dati sui "bacini" murati nelle chiese medievali e post-medievali in Albania, in Hortus Artium Medievalium, vol. 21, 2015, pp. 366-384, in partic. pp. 371-372.

${ }^{99}$ Filippo d'Angiò oltre a prendere in moglie Tamara d'Epiro venne investito dal padre, oltre che del Principato di Taranto, anche dei [...] principatu Achaie, ducatu Athenarum, regnio Albanie, provincia Wlachie ac ceteris locis imperii seu partium Romanie tam in terra firma quam in insulis ex quacumque causa iuro vel titulo nobis nunc competunt et possent competere in futurum, donat in pheudum [...]. É.G., LÉONARD, op. cit. (n. 90), pp. 243-246. T. FRACHERY, op. cit., (n. 9o), p. 15, nota 32.

${ }^{100}$ A. MEKSI, op. cit. (n. 24), pp. 235-240, in partic. pp. 239-240.

${ }^{100}$ È parte di un ciclo che, per dettagli e schemi compositivi, culti e stile pittorico, è possibile identificare nell'ambito della maniera greca, non dissimile dalla coeva produzione della sponda dell'Italia meridionale. G. CAMPOBASSO op. cit. (n. 3).

${ }^{102}$ D. RADOJIČIĆ, Un poème épique yougoslave du XI e siècle. Les "gestes" ou exploits de Vladimir, prince de Dioclée, in Byzantion, 35, 1965, pp. 528-535. A. DUCELLIER, op. cit. (n. 5), p. 93; R. ELSIE, v. ad vocem John Vladimir, Saint, in op. cit. (n. 64), pp. 139-140. P. STEPHENSON (dir.), Chronicle of the Priest of Duklja, capitolo 36, online: http://web.archive.org/web/20110513234451/http://homepage.mac.com/paulstephenson/trans/lpdi.html.

${ }^{103}$ R. ELSIE, op. cit. (n. 102). 


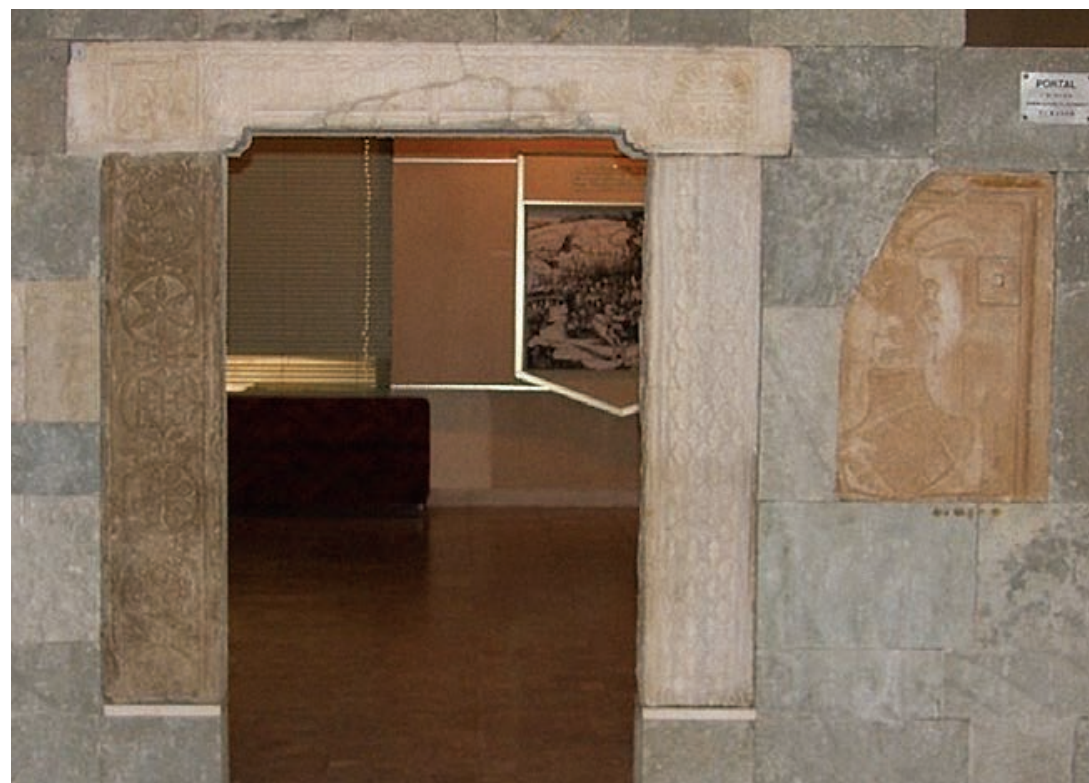

Fig. 29. Tirana, Museo Nazionale, "portale" del katholikon di S. Giovanni Vladimiro.

\section{FILIO P(RI)MO GENITO D(OMI)NO GEORGIO HA(N)C ECCLE(ESI)AM FECIT}

Il fondatore è celebrato nelle epigrafi che insistono sulla sua genealogia e sui suoi titoli e costituiscono un'importante traccia che configura il santuario come un luogo sacro condiviso fra le diverse comunità etnico-linguistiche che vi si recavano in pellegrinaggio ${ }^{105}$. A seguito delle due traslazioni, il culto dovette diffondersi in tutta l'Albania; da qui la sua ecumenicità, che abbracciava tanto l'ambito cattolico, sia ortodosso e che si avvantaggiò degli antichi assi stradali, da quello costiero all'Egnatia. La fama del martire fu certamente un tramite di promozione personale per Carlo Thopia, il quale si poneva sotto la protezione di questo santo-re, alimentando una sorta di analogia, o millantando un'antica discendenza, al fine di santificare la sua stirpe e la sua opera politica attraverso una sorta di culto dinastico, meccanismo concettuale ben noto e manipolato dalla Maison d'Anjou, a cui lo stesso Thopia apparteneva.

Coerente con le iscrizioni e con l'immagine che l'edificio ed il santo contribuivano a diffondere è l'articolata composizione araldica, scolpita su una targa rettangolare che difatti svela i natali angioini di Carlo Thopia ${ }^{106}$. Spicca uno scudo semipartito con le armi dei principi di Taranto e imperatori di Costantinopoli, utilizzate dal 1313, da quando Filippo, alcuni anni dopo aver ripudiato Tamara d'Epiro, sposò Caterina di Valois Courtenais erede nominale dell'Impero latino ${ }^{107}$. Nel rilievo lo scudo è poi avvolto da un mantello gigliato che regge un suppedaneo su cui poggia un leone rampante con corona gigliata e piumata, e va rilevata questa profusione di regalia utilizzati dai sovrani francesi, insieme alle piume, segno di distinzione e comando nel mondo balcanico.

Oltre che nella targa araldica, il motivo del fleur de lis è ripreso in senso decorativo nello "stipite" destro del cosiddetto portale, ma l'originaria provenienza di quell'elemento architettonico è da ricercare altrove, estraneo com'è alla ricomposizione. Trattasi di un lungo segmento di pietra bruna (mentre architrave e stipite opposto sono in pietra candida) che reca scolpito una sequenza di orbicoli contenenti motivi pseudo-fioriti alternati a piccoli nodi di raccordo dai quali sbocciano gigli.

Questo tipo di decorazione orbicolare, prevalentemente aniconica, trovò abbondante utilizzo e facile diffusione tramite gli ornati delle stoffe prodotte nel Levante mediterraneo. Da secoli era divenuta un consolidato e frequente repertorio della plastica bizantina, impiegata nelle parti lapidee del templon ${ }^{108}$. Tale elemento d'arredo aveva lo scopo di dividere, nelle chiese di rito greco, lo spazio dei fedeli da quello liturgico, o meglio della manifestazione del sacro, ed

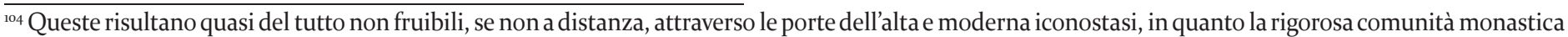
che vi officia tuttora non permette l'accesso al bema di visitatori e studiosi.

${ }^{105}$ S. Giovanni Vladimiro era venerato innanzitutto dai Serbi di Dioclea di cui fu sovrano. R. ELSIE, op. cit. (n. 102).

${ }^{106}$ Secondo il Léonard era nato dall'unione di una figlia di Filippo di Taranto ed un potente aristocratico albanese. É.G., LÉONARD, op. cit. (n. 90), tav. 4.

${ }^{107}$ Quelle armi sono state riconosciute a Santa Maria del Casale, nota committenza tarantina, in cui le cronache locali riportano una cappella imperiale, cfr. G. PERRINO, op. cit. (n. 92), pp. 91-94; G. CURZI, op. cit. (n. 92 ), pp. 71-78; sul portale maggiore della cattedrale d'Altamura, cfr. P. BELLI D’ELIA, La facciata ed il portale della cattedrale di Altamura: riletture e riflessioni, in Altamura, 36, 1994-1995, pp. 215-245, e in talune miniature d'ambito tarantino come quelle del noto codice degli Statuti dell'Ordine del Nodo (Parigi, Bibliotèque Nationale, ms. Fr. 4274).

${ }^{108}$ Cfr. A. GRABAR, Sculptures byzantines du Moyen Age (XIe-XIVe siècle), Paris 1976. Frammenti dell'iconostasi sono anche reimpiegati in uno dei portali della chiesa delle Blacherne di Arta. C. MANGO, op. cit. (n. 94), pp. 256-257, 259.
} 
il bassissimo rilievo del frammento in questione, prezioso ed elegante, trovava un'ideale continuazione nei ricami dei velaria che celavano gli intercolumni di quelle strutture. I veli e per analogia la decorazione associabile ai tessuti, avevano una funzione liminale spartendo gli spazi, naos e bema e quindi l'umano dal divino, determinando la sacralizzazione di quello che non era visibile, o centellinato alla vista, e che si manifestava agli altri sensi oltre quella barriera ${ }^{109}$. Il giglio di Francia, pur estrapolato da un'altra cultura visiva, trova inclusione in questa composizione in quanto anch'esso ebbe fra i suoi maggiori media proprio stoffe e tessuti usati tanto nella liturgia del potere, quanto in quella religiosa, come mostrano molte miniature d'ambito francese e napoletano del XIV secolo. La composizione araldica del seminato di gigli in campo azzurro era una metafora del cosmo, allusione divina e contemporaneamente all'universalità del potere regale $^{110}$. Questa lettura duplice fra l'umano e il divino, fra il sacro e il politico, contribuì a rendere il giglio un simbolo "liminale", per questo adatto a scompartire gli spazi liturgici come il bema e il naos. Nel primo, tramite un'adeguata regia veniva simulata la manifestazione di Dio, mentre il secondo era lo spazio dei laici legato alla realtà sensibile. L'intensa devozione che si manifestava all'ingresso del regno dell'inaccessibile, cioè davanti al tramezzo, si dirigeva anche verso le insegne del potere. La simulazione e celebrazione della presenza divina e del santo dedicatario ad Elbasan chiamava in causa lo stesso fondatore che ne beneficiava indirettamente. La mise-en-scène o la regia del sacro, forse più che a Rubik, si ammantava di forti connotati politici. L'aura di sacralità che promanava dal sepolcro del santo, dal bema celato, dalla liturgia e dall'universo di simbolismi e ritualistica investiva lo spazio religioso ed il Thopia. Tutto concorreva a ribadire la sua indiscutibile liceità a governare sulle molteplici componenti etnico-linguistiche di quel feudo, approfittando del valore ecumenico di S. Giovanni Vladimiro e ostentando i suoi natali regali (de domo Franciae) nell'ambito della beata stirps angioina.
Nonostante l'orientamento vario dei territori albanesi, con l'estremo nord cattolico e contiguo alla Dalmatia, il centro configurato come unarea cuscinetto sostanzialmente biconfessionale ed il sud più radicato nel culto greco, come si è visto i fenomeni qui presi in esame chiamano in causa una circolazione ben più ampia e che trascende i confini culturali.

Imbevuta anche da simbolismi e immagini mentali provenienti dalla cultura visiva d'Occidente, è evidente come l'arte albanese del tardo medioevo sia alla confluenza di più radici, con un innegabile substrato bizantino alla base. L'ampiezza della problematica toccata in questo saggio mi ha imposto una selezione che si è concentrata su alcuni esempi di architettura e scultura, seguendo una direttrice da Ovest a Est, ma il naturale "bilinguismo" delle coste adriatiche, specialmente quelle meridionali, ovviamente ha offerto ed offre tuttora occasioni di studio, anche per quanto riguarda transfer inversi.

Gli scambi, com'è noto, non furono certo a senso unico, come dimostra la perizia e lo sviluppo che acquisì anche la "scuola dalmata" nelle arti monumentali, esportando artisti e modelli da cui l'arte italiana trasse giovamento. Valgano per tutti i casi pugliesi di Simeon Raguseus incola tranensis autore nel XIII secolo di una splendida lunetta nel portale della chiesa di S. Andrea di Barletta ${ }^{\mathrm{II}}$; fino al trapianto di formule della tradizione decorativa e dell'architettura dalmate nelle cattedrali di Gravina e Ostuni, nella matrice di Mola di Bari o nelle chiese di Monopoli, solo per citare alcuni esempi ancora fra Quattro e Cinquecento ${ }^{112}$.

Fra i magistri, che in età tarda si spostavano fra le due sponde adriatiche, inesistenti i casi d'individui d'estrazione albanese, per quanto, quasi a chiudere il cerchio di questo nostro giro d'orizzonti, si colloca la rifioritura dell'abbazia di S. Maria a mare di Tremiti. Ormai sotto i Canonici Regolari Lateranensi di S. Agostino, questi ne rinnovarono l'architettura nel XV secolo impiegando magistri di cultura tosco-dalmata: Niccolò di Giovanni, fiorentino proveniente da Ragusa, ed Andrea Alessi da Durazzo"13. Ma qui comincia un'altra storia, quella appunto dei transfer contrari che ebbero un notevole peso nel Rinascimento italiano.

\footnotetext{
${ }^{109}$ M. BACCI, Lo spazio dell'anima. Vita di una chiesa medievale, Roma-Bari 2005, p. 185. IDEM, op. cit. (n. 95), pp. 617-624. Ma anche L. USPENSKIJ - V. LOSSKIJ, Il senso delle icone, Milano 2007, pp. 70-71. V. RUGGERI, La barriera presbiterale e il templon bizantino: ambivalenze semantiche fra liturgia, architettura e scultura, in Bizantinistica, Rivista di studi bizantini e slavi, Serie Seconda, Anno 10 - 2008, edito 2009, pp. 29-59 e tavv.

${ }^{\text {nо }}$ M. PASTOUREAU, Bleu... op. cit. (n. 55); IDEM, Un fiore... op. cit. (n. 55).

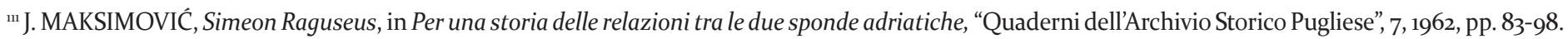
${ }^{112}$ M. S. CALÒ MARIANI, Monopoli e le correnti dell'arte tra Medioevo e Rinascimento. In Monopoli nell'Età del Rinascimento, atti del Convegno Internazionale di studio (22-24 marzo 1985), Monopoli 1988, pp. 627-679.

${ }^{{ }_{13}}$ V. FORETIĆ, op. cit. (n. 20), pp. 130-144. Per le vicende costruttive dell'abbazia nelle sue varie fasi: A. PEPE, Sulle relazioni artistiche tra la Puglia e la Dalmazia: Andrea Alessi da Durazzo e Niccolò Fiorentino a S. Maria delle Tremiti, in L'Adriatico e il Gargano, V Convegno Storico (Rodi Garganico 10-11 maggio 1986), Rodi 1988, pp. 21-38. C. RADICCHIO, L'isola di San Nicola di Tremiti, Bari 1993. A. PEPE, Architettura in Capitanata fra Quattro e Cinquecento. Gli interventi rinascimentali in S. Maria delle Tremiti, in $18^{\circ}$ Convegno Nazionale sulla Preistoria - Protostoria - Storia della Daunia (San Severo 29 - 30 novembre 1997), San Severo 1999, pp. 123-146. P. BELLI D’ELIA, Puglia romanica, Milano 2003, pp. 29-39.
}

** Quando non diversamente indicato le foto sono dell'autore. 
VENICE, BYZANTIUM 